\title{
HYBRID COOPERATION AGREEMENTS IN NETWORKS: THE CASE OF THE AIRLINE INDUSTRY
}

\author{
Xavier Fageda, ${ }^{*}$ Ricardo Flores-Fillol,${ }^{\dagger}$ And Bernd Theilen ${ }^{\ddagger}$
}

October 2017

\begin{abstract}
This paper develops a unified framework to analyze a continuum of hybrid cooperation agreements along two dimensions: their degree of revenue sharing (scope of alliances) and their degree of cost sharing (scope of joint ventures). The analysis focuses on the air transportation industry, distinguishing between interline and interhub markets. As economies of traffic density become stronger, we find that the socially optimal cooperation agreement moves from full alliance to joint venture in interline markets, whereas it moves from joint venture to merger in interhub markets. These results are driven by the tradeoff between a procompetitive effect of alliances in interline markets and an anticompetitive effect in interhub markets, along with the efficiency gains associated with joint ventures in interhub markets. We also develop an empirical application for intercontinental routes for the period 2010-2016 that identifies a positive impact of deeper degrees of airline cooperation (revenue and cost sharing) on traffic, both in interline and interhub markets. Therefore, the potential anticompetitive effect of deeper alliances in interhub markets is not observed in our sample.
\end{abstract}

Keywords: hybrid cooperation agreements; airline industry; alliances; joint ventures; mergers.

JEL Classification Numbers: L13; L22; L93.

*Department of Economic Policy, Universitat de Barcelona, Avinguda Diagonal 690, 08034 Barcelona, Spain. Tel.: +34934039721; e-mail: xfageda@ub.edu.

${ }^{\dagger}$ Departament d'Economia and CREIP, Universitat Rovira i Virgili, Avinguda de la Universitat 1, 43204 Reus, Spain. Tel.: +34977759851; e-mail: ricardo.flores@urv.cat.

${ }^{\ddagger}$ Departament d’Economia and CREIP, Universitat Rovira i Virgili, Avinguda de la Universitat 1, 43204 Reus, Spain. Tel.: +34977759813; e-mail: bernd.theilen@urv.cat. 


\section{Introduction}

The air transportation industry is characterized by a strong competitive pressure that requires airlines to innovate permanently. While innovation affects many dimensions (such as the adoption of new aircraft technologies and business models or the implementation of novel yield management practices), one of its main consequences has been the proliferation of sophisticated and complex hybrid agreements among airlines in recent years. ${ }^{1}$ This trend has also been reinforced by the existence of regulatory restrictions on foreign ownership of airlines, which has prevented the formation of full mergers at the international level. ${ }^{2}$ In fact, intercontinental routes are generally operated by airlines integrated in one of the three major global alliances (Oneworld, SkyTeam, and Star Alliance).

Alliance members usually cooperate in various dimensions to exploit revenue synergies such as codesharing agreements, mutual recognition of frequent-flyer programs, and a number of facilities so as to provide a seamless service to interline passengers (e.g., coordination of flight schedules, shared lounge access, and gate proximity). In particular, a standard codesharing agreement allows one carrier to market under its two-letter designator code a certain number of seats on a flight operated by a different carrier. Moreover, some airlines within an alliance may also attain deeper degrees of cooperation on specific international routes when they are granted antitrust immunity (ATI) by competition authorities, allowing partner carriers to cooperatively make scheduling and pricing decisions. ${ }^{3}$ For instance, ATI has been granted to Star Alliance partner airlines on their flights in the city-pair market between San Francisco and Seoul in 2003.

Another trend in airline cooperation, which also implies a deeper level of revenue sharing than a standard alliance, is the so-called equity alliances. Through these type of agreements, one airline obtains a certain degree of control over another airline through the purchase of equity shares. As long as the proportion of capital acquired does not exceed 49\%, this type of agreement escapes from existing national restrictions on foreign ownership. Recent examples of equity alliances are, for instance, the purchase of shares of Air Berlin and Alitalia by Etihad or the purchase of shares of IAG by Qatar Airways.

Finally, hybrid airline cooperation agreements can also take the form of joint ventures, which allow partners to attain a certain degree of cost sharing on particular routes (Thomas and Catling, 2014). Cooperation in the realm of costs translates into the exploitation of synergies through the joint purchase of fuel, ground handling, catering and other supplies, and the joint use of marketing and global distribution systems (GDS). At the same time, joint ventures may also convey a deeper revenue sharing, allowing airlines to coordinate schedules, prices, and capacities more closely than just cooperating through an alliance. ${ }^{4}$ The deepest joint ventures that can be attained are based on the principle of metal neutrality, implying that both revenues 
and costs are shared proportionally no matter which airline actually operates the flights on a route, so that they are akin to merger-like agreements. Some examples of joint ventures are the agreement between Delta and its European SkyTeam partners (Air France-KLM and Alitalia) or the cooperation between Delta and Virgin Atlantic on transatlantic routes.

The impact on consumer welfare of these hybrid cooperation agreements is difficult to assess because most carriers are multi-product firms that operate in several markets characterized by different degrees of competition intensity. Furthermore, airlines may exhibit economies of traffic density on certain routes while they may experience decreasing returns on other routes (typically dense routes affected by airport congestion). As a consequence, the effect of these agreements might be procompetitive in one market but anticompetitive in another.

The objective of this work is to provide a general analysis, both theoretical and empirical, of the existing hybrid forms of cooperation in air transportation markets, from soft alliances to merger-like joint ventures. Taking into account the airlines' generalized use of hub-and-spoke networks, the analysis has to differentiate two main types of markets: interline and interhub.

In the theoretical part, we develop a unified framework to analyze a continuum of hybrid cooperation agreements along two dimensions: their degree of revenue sharing (scope of alliances) and their degree of cost sharing (scope of joint ventures). We first analyze airline optimal choices in both markets (interline and interhub) under different hybrid cooperation agreements, and then study the differentiated effect of these agreements on consumer welfare. ${ }^{5}$ There is demand for connecting flights in the interline market, where there are two complementary air services, each of them provided by a different monopoly firm. Differently, there is direct duopoly competition in the interhub market where airline networks overlap.

In the empirical part, we use quarterly data for the period 2010-2016 at airline-route level, focusing on intercontinental routes characterized by a rich variation in the degree of airline cooperation (16, 897 observations with complete information for all variables). We estimate a gravity model where passenger traffic for interhub and interline markets is regressed on variables measuring different degrees of airline cooperation (including ATI agreements, equity alliances, and joint ventures). We include as controls the distance of the non-stop route, variables for the economic and demographic size of the endpoints, and different specific fixed effects.

Our theoretical results are summarized as follows. First, under decreasing returns, deeper alliances have a positive effect on traffic in the interline market and a negative effect in the interhub market. Second, under economies of traffic density, the effect of deeper joint ventures on traffic is positive in both markets. Third, the socially optimal cooperation agreement in the interline market is: $i$ ) full alliance in the presence of decreasing returns (either weak or strong); ii) joint venture with full revenue sharing under constant returns; iii) merger in the presence of weak economies of traffic density; and iv) joint venture for strong economies of traffic density. 
The intuition behind this result is that alliances have a positive effect on consumer welfare because they allow internalizing a double marginalization externality but, simultaneously, an adverse cost effect can arise under strong economies of traffic density due to a fall of traffic in the interhub market that increases marginal costs and can result in higher prices and lower traffic volumes in both markets. Fourth, the socially optimal cooperation agreement in the interhub market is: i) merger in the presence of strong economies of traffic density, and ii) joint venture otherwise. The reason is that, as economies of traffic density become stronger, the effect of deeper joint ventures on consumer welfare is increasingly positive because it translates into higher efficiency gains. The joint consideration of the interhub and the interline markets elucidates the importance of market-size asymmetry and cost technologies in the assessment of the net welfare effect of cooperation agreements.

The results of our empirical application show that deeper degrees of airline cooperation (revenue and cost sharing) have a positive impact on traffic both in interline and interhub markets. While these results are in general consistent with the existence of economies of traffic density, they also suggest that deeper alliances and joint ventures may also have a positive impact on traffic under decreasing returns. Therefore, the potential anticompetitive effect of deeper alliances in interhub markets is not observed in our sample.

The paper is organized as follows. In Section 2 we review the existing literature, while in Section 3 we set up our theoretical model. Section 4 contains the theoretical results of the paper and, in Section 5, we elucidate the net welfare effect of cooperation agreements by means of a numerical simulation. Section 6 contains our empirical application using data from intercontinental air transportation services. Finally, Section 7 concludes with a discussion on the generality of the results and challenges for future research. All proofs are provided in the Appendix.

\section{Literature review}

The theoretical literature is rather scarce and has mainly focused on the study of airline alliances. While Brueckner (2001) analyzes the effect of alliances on fares, Flores-Fillol and Moner-Colonques (2007) focus on their profitability using a game-theoretic approach. Finally, Brueckner and Proost (2010) study the effect of carve-outs, which aim at correcting the potential anticompetitive effects of ATI agreements. ${ }^{6}$

The empirical literature is richer and has studied both alliances and mergers. Several studies have examined the impact of alliances on prices and output in international markets (mainly in the transatlantic market). In interhub markets, no clear evidence has been found about the 
potential anticompetitive effects of alliances. Oum et al. (1996) find that codesharing agreements between non-leader airlines increase output and reduce fares of the market leader airline. Park and Zhang (1998) show that traffic of partner airlines increases on the alliance routes more than on the non-alliance routes. Brueckner and Whalen (2000) do not find statistically significant increases in fares caused by an alliance between two previously competitive carriers. By contrast, Gillespie and Richard (2012) obtain that granting ATI to two competing non-stop carriers has a fare effect that is equivalent to the loss of an independent competitor, and fares are significantly higher in markets with fewer independent competitors. Finally, Bilotkach and Hüschelrath (2013) show that ATI agreements produce a traffic increase on interhub routes operated by the alliance members, whereas a traffic reduction is observed on routes operated by non-partner airlines that connect other endpoints with the partners' hubs. In interline markets, the evidence is clearly in favor of the hypothesis that incremental levels of cooperation between airlines (mainly, codesharing and ATI) lead to fare reductions. This conclusion can be inferred from the results obtained in the studies made by Brueckner and Whalen (2000), Brueckner (2003), Whalen (2007), Brueckner et al. (2011), and Calzaretta et al. (2017). ${ }^{7}$ Whalen (2007) also finds that alliances are associated with large increases in passenger volumes. The reason underlying the fare reduction is the elimination of the double marginalization externality that arises when airlines are unallied.

The first wave of US mergers (in the 1980s) has been empirically examined by Borenstein (1990), Kim and Singal (1993), and Kwoka and Shumilkina (2010). These studies focus on the price and market power effects of mergers. Recent studies have also analyzed the impact of the latest US airline mergers. Bilotkach (2011) shows that the US Airways/America West merger did have an effect on flight frequency because of the resulting change in the level of multimarket contact. Bilotkach et al. (2013) propose a model with vertically-differentiated airlines to analyze the Delta/Northwest merger, observing a concentration of traffic in Delta's primary hubs after consolidation. Luo (2014) provides an analysis of the price effects of the Delta/Northwest merger. She finds that this consolidation event did not lead to significant fare increases on individual routes where the merger partners used to compete. Finally, Shen (2017) uses a difference-in-differences model to examine the price effects of the United/Continental merger, finding an increase in fares on non-stop routes affected by the merger. European airline mergers remain largely unstudied, due to relatively poor data availability. Dobson and Piga (2013) analyze business model assimilation following mergers between European low-cost carriers. Finally, Fageda and Perdiguero (2014) identify asymmetric effects of a merger involving three Spanish airlines, depending on each airline's business model (network or low-cost).

The main novelty of our analysis is to put the focus on the unexplored field of hybrid cooperation agreements (where the literature is basically nonexistent) and the use of a unique 
dataset with information on non-stop and connecting passengers on intercontinental routes, characterized by a rich variation in the degree of airline cooperation. Three main aspects need to be taken into account to carry out our analysis: $i$ ) the differentiation between revenue and cost-sharing agreements, $i i$ ) the distinction between interhub and interline markets, and $i i i$ ) the consideration of both economies of traffic density and decreasing returns (which can be caused by airport congestion).

\section{The model}

\subsection{Network}

We assume a simple 2-airline-2-hub network that includes one interhub and one interline market, as observed in Fig. 1. The interhub market (hereafter market $\mathrm{H}$ ) comprises all trips between hub airports $H_{1}$ and $H_{2}$ and the interline market (hereafter market $\mathrm{S}$ ) encompasses trips between spoke airports $S_{1 k}$ and $S_{2 \ell}$. For simplicity, we assume no market demand in the remaining potential markets (i.e., markets $S_{1 k^{-}} H_{1}, S_{1 k^{-}} H_{2}, S_{2 \ell^{-}} H_{1}, S_{2 \ell^{-}} H_{2}$ ) since the inclusion of these markets does not provide any relevant insight and distracts attention from the main economic intuitions that affect markets $\mathrm{H}$ and $\mathrm{S} .{ }^{8}$

- Insert Fig. 1 about here -

All trips initiated in spoke $S_{1 k}$ are carried out by airline 1, whereas all trips initiated in spoke $S_{2 \ell}$ are carried out by airline 2 . Thus, there is a demand for a composite good (or system) in market $\mathrm{S}$, where each complementary input is provided by a different monopoly firm (e.g., a trip initiated at spoke $S_{1 k}$ is composed by a service between $S_{1 k}$ and $H_{2}$ provided by airline 1 and another complementary service between $H_{2}$ and $S_{2 \ell}$ provided by airline 2). By contrast, carriers compete in market $\mathrm{H}$ where there is network overlap. Finally, we also assume that all outbound trips come along with the corresponding return service, i.e., they are round trips. This allows to treat equally all passengers in market $\mathrm{S}$ independently of whether they are located in spoke $S_{1 k}$ or $S_{2 \ell} \cdot{ }^{9}$

\subsection{Revenues}

Let us denote fares and quantities in markets $\mathrm{H}$ and $\mathrm{S}$ by $p_{H}, p_{S}, q_{H}$, and $q_{S}$. Direct and inverse demand functions in both markets are assumed to be identical and given by $d(\cdot)$ and $D(\cdot)$, respectively. ${ }^{10}$ Airlines are assumed to be symmetric. Competition in market $\mathrm{H}$ is $\grave{a} l a$ Cournot, i.e., carrier $i$ chooses its quantity $q_{H}^{i}$ to maximize profits. By contrast, as in market 
$\mathrm{S}$ there is an demand for a composite good, carrier $i$ chooses monopolistically a subfare $p_{S}^{i}$ for its complementary input, so that the total fare in this market is $p_{S}^{i}+p_{S}^{j}$, with $i, j=1,2$ and $i \neq j .{ }^{11}$ Therefore, the total revenue for airline $i$ can be written as

$$
R^{i}=p_{S}^{i} d\left(p_{S}^{i}+p_{S}^{j}\right)+D\left(q_{H}^{i}+q_{H}^{j}\right) q_{H}^{i} .
$$

\subsection{Costs}

In network analysis, while revenues are associated with markets, costs are related to links or routes. A carrier's operating cost on a route can be decomposed into several components related to the purchase of fuel, ground handling, catering and other supplies or marketing and GDS. Carrier $i$ 's cost function is assumed to be additively separable in these cost components, which are given by $C_{m}=a_{m} C[Q]$, with $m=1, \ldots, M$ and $Q$ being the total traffic carried by

the airline on this route. Normalizing $\sum_{m=1}^{M} a_{m}=1$, the cost borne by each airline on a route becomes $\sum_{m=1}^{M} C_{m}=C[Q] \cdot{ }^{12}$

Each airline bears the cost $C[Q]$ of operating the spoke-to-hub routes and the hub-to-hub route, where $C^{\prime}>0$ and $C^{\prime \prime} \lesseqgtr 0$. Therefore, the analysis encompasses the following cases: economies of traffic density $\left(C^{\prime \prime}<0\right)$, constant returns $\left(C^{\prime \prime}=0\right)$, and decreasing returns $\left(C^{\prime \prime}>0\right)$. The latter case typically arises in the presence of airport congestion.

The cost of operating a route stems from the total traffic that passes through it. In particular, total traffic on the hub-to-hub route is the sum of traffic in markets $\mathrm{S}$ and $\mathrm{H}$, while traffic on spoke-to-hub routes comes exclusively from market S. Furthermore, the existing duopoly competition in market $\mathrm{H}$ can be affected by cost-sharing agreements, such as joint ventures and mergers.

A joint venture implies partial cost sharing on a certain route where the two carriers work together while they remain separate entities. Such agreements are halfway between the polar cases of independent firms (no cost sharing) and a merger (full cost sharing). More precisely, joint ventures involve cooperation on certain cost components implying, e.g., joint purchase of fuel, ground handling, catering and other supplies or joint use of marketing and GDS.

At this point, denoting $C_{H H}^{i}$ airline $i$ 's cost related to operating the hub-to-hub route, we can distinguish three cases depending on the presence and intensity of cost sharing on this route: i) Absence of joint ventures (i.e., no cost sharing), where $C_{H H}^{i}=C\left[q_{S}^{i}+q_{H}^{j}\right]$.

ii) Merger (i.e., full cost sharing), where $C_{H H}^{i}=C\left[q_{S}+q_{H}\right] / 2 .{ }^{13}$ This is the case of a merger of equals where there is a joint cost that is shared 50/50 between the two airline partners. ${ }^{14}$ iii) Joint venture (i.e., partial cost sharing), where there is cooperation on some cost components $m=1, \ldots, \omega$ while the rest of components $m=\omega+1, \ldots, M$ remain independently 
borne by each airline, so that $C_{H H}^{i}=\sum_{m=1}^{\omega} a_{m} C\left[q_{S}+q_{H}\right] / 2+\sum_{m=\omega+1}^{M} a_{m} C\left[q_{S}^{i}+q_{H}^{i}\right]$. Denoting $\mu \in[0,1]$ the scope of joint ventures, understood as the share of cost components on which there is airline cooperation (i.e., $\mu \equiv \sum_{m=1}^{\omega} a_{m}$ ), the above cost function becomes $C_{H H}^{i}=$ $\mu C\left[q_{S}+q_{H}\right] / 2+(1-\mu) C\left[q_{S}^{i}+q_{H}^{i}\right] \cdot{ }^{15}$

The presence of economies of traffic density $\left(C^{\prime \prime}<0\right)$ creates cost synergies from pooling resources and $C\left[q_{S}+q_{H}\right] / 2<C\left[\left(q_{S}+q_{H}\right) / 2\right]$ can be observed. In such a case, deeper costsharing agreements become more advantageous. Regarding decreasing returns, it is assumed that they are bounded from above in the following way: $C^{\prime}\left[\frac{q_{S}+q_{H}}{2}\right]>\frac{C^{\prime}\left[q_{S}+q_{H}\right]}{2} .{ }^{16}$ In general terms, carrier $i$ 's overall cost is given by

$$
C^{i}=\underbrace{C\left[q_{S}\right]}_{C_{S H}^{i}}+\underbrace{\mu C\left[q_{S}+q_{H}\right] / 2+(1-\mu) C\left[q_{S}^{i}+q_{H}^{i}\right]}_{C_{H H}^{i}}
$$

where $C_{S H}^{i}$ denotes airline $i$ 's cost related to operating the spoke-to-hub route and the aforementioned three cost-sharing agreements on the hub-to-hub route can be derived. ${ }^{17}$ Using $q_{S}^{i}=\frac{d\left(p_{S}^{i}+p_{S}^{j}\right)}{2}, q_{S}=d\left(p_{S}^{i}+p_{S}^{j}\right)$, and $q_{H}=q_{H}^{i}+q_{H}^{j}$, the overall cost in (2) can be rewritten as

$$
C^{i}=C\left[d\left(p_{S}^{i}+p_{S}^{j}\right)\right]+(1-\mu) C\left[\frac{d\left(p_{S}^{i}+p_{S}^{j}\right)}{2}+q_{H}^{i}\right]+\mu \frac{C\left[d\left(p_{S}^{i}+p_{S}^{j}\right)+q_{H}^{i}+q_{H}^{j}\right]}{2} .
$$

\subsection{A unified model of cooperation agreements}

Airline cooperation agreements may involve revenue sharing and/or cost sharing. Revenuesharing partnerships are modeled as cross-equity (or cross-ownership) agreements. ${ }^{18}$ We denote $\delta$ the scope of alliances with $\delta \in[0,1]$, so that airline $i$ 's profit is

$$
\Pi^{i}=\pi^{i}+\delta \pi^{j}
$$

where $\pi^{i}=R^{i}-C^{i}=p_{S}^{i} d\left(p_{S}^{i}+p_{S}^{j}\right)+D\left(q_{H}^{i}+q_{H}^{j}\right) q_{H}^{i}-C\left[q_{S}\right]-\mu C\left[q_{S}+q_{H}\right] / 2-(1-\mu) C\left[q_{S}^{i}+q_{H}^{i}\right]$. Alternatively, alliances can also be interpreted as revenue-sharing agreements in a proportion $\delta$ of traffic in markets $\mathrm{S}$ and $\mathrm{H}^{19}$ Recognizing that $q_{S}=d\left(p_{S}\right), p_{S}=D\left(q_{S}\right), D^{\prime}\left(q_{S}\right)=1 / d^{\prime}\left(p_{S}\right)$ and focusing on the symmetric equilibrium where $q_{H}^{1}=q_{H}^{2}=q_{H} / 2$ and $p_{S}^{1}=p_{S}^{2}=p_{S} / 2$, the maximization of $\Pi^{i}$ choosing $p_{S}^{i}$ and $q_{H}^{i}$ yields two first-order conditions that can be rewritten as

$$
\begin{aligned}
\Lambda_{S} & \equiv \frac{2}{1+\delta} q_{S} D^{\prime}\left(q_{S}\right)+D\left(q_{S}\right)-2 C^{\prime}\left[q_{S}\right]-(1-\mu) C^{\prime}\left[\frac{q_{S}+q_{H}}{2}\right]-\mu C^{\prime}\left[q_{S}+q_{H}\right]=0 \\
\Lambda_{H} & \equiv D\left(q_{H}\right)+\frac{1+\delta}{2} q_{H} D^{\prime}\left(q_{H}\right)-(1-\mu) C^{\prime}\left[\frac{q_{S}+q_{H}}{2}\right]-(1+\delta) \mu \frac{C^{\prime}\left[q_{S}+q_{H}\right]}{2}=0
\end{aligned}
$$


The analysis of the second-order conditions is discussed in the following section. Depending on the values of $\mu$ and $\delta$, the following types of cooperation agreements can be derived.

1. Independent firms: $\mu=0$ and $\delta=0$. In this case, there is no revenue or cost sharing. The only cooperation that exists in this scenario consists in the needed coordination in providing the composite good in market $\mathrm{S}$, where each firm provides monopolistically a complementary input.

2. Soft alliance: $\mu=0$ and $\delta \in(0,1)$. Soft alliances are partial revenue-sharing agreements where there is some degree of cross-ownership (or cross-equity).

3. Full alliance: $\mu=0$ and $\delta=1$. In this scenario, there is full revenue sharing, i.e., airlines maximize joint profits. However, costs on the hub-to-hub link remain firm specific, i.e., firms cannot pool traffic and eliminate one of the links between hubs.

4. Joint venture: $\mu \in(0,1)$ and $\delta \in(0,1)$ with $\mu \leqslant \delta$. Revenue sharing constitutes a necessary condition to implement cost sharing. At this point, we assume $\mu \leqslant \delta$ since a joint venture constitutes a step further in terms of cooperation (involving both revenue and cost sharing) as compared to an alliance (which just involves revenue sharing). ${ }^{20}$

5. Joint venture with full revenue sharing: $\mu \in(0,1)$ and $\delta=1$. Under this cooperation agreement, a part from full revenue sharing, cooperation also involves some partial cost sharing.

6. Merger: $\mu=1$ and $\delta=1$. A merger is a full joint venture where both firms constitute a new monopoly entity that operates alone in markets $\mathrm{S}$ and $\mathrm{H}$.

This unified model allows studying the welfare effects associated with hybrid cooperation agreements, which are increasingly observed in the airline industry. Interestingly, the model could also be adapted to accommodate the potential presence of carve-outs. Carve-outs are intended to correct for the possible anticompetitive effects of alliances in the interhub market (where there is network overlap) by preventing revenue sharing between alliance partners when they are endowed with ATI. In terms of our model, for airline $i$, this would require to introduce a new parameter $\gamma \in[0,1]$ in the interhub revenues coming from its partner airline (i.e., in $\left.\pi^{j}\right) .{ }^{21}$ This would have no effect on (5), while (6) would become $D\left(q_{H}\right)+\frac{1+\delta \gamma}{2} q_{H} D^{\prime}\left(q_{H}\right)-$ $(1-\mu) C^{\prime}\left[\frac{q_{S}+q_{H}}{2}\right]-(1+\delta) \mu \frac{C^{\prime}\left[q_{S}+q_{H}\right]}{2}=0$. A full alliance with a carve-out would be obtained for $\delta=1, \mu=0$, and $\gamma=0$, recovering the result in Brueckner and Proost (2010). ${ }^{22}$ As the effect of carve-outs is already analyzed in detail in the aforementioned study and would divert attention from the main focus of our analysis (which is to study hybrid cooperation agreements), we have 
refrained from incorporating this additional parameter that would complicate the exposition of our main results. ${ }^{23}$

\section{The effect of alliances and joint ventures}

As suggested above, the scope of alliances $(\delta)$ and the scope of joint ventures $(\mu)$ allow distinguishing the different kinds of cooperation agreements. In this section, we analyze the effect of $\delta$ and $\mu$ on traffic and consumer welfare in markets $\mathrm{S}$ and $\mathrm{H}$.

\subsection{The effect of alliances on traffic}

The following conditions are assumed to hold

$$
\begin{gathered}
\frac{\partial \Lambda_{S}}{\partial q_{S}}<0, \frac{\partial \Lambda_{H}}{\partial q_{H}}<0, \\
\Gamma \equiv \frac{\partial \Lambda_{S}}{\partial q_{S}} \frac{\partial \Lambda_{H}}{\partial q_{H}}-\frac{\partial \Lambda_{S}}{\partial q_{H}} \frac{\partial \Lambda_{H}}{\partial q_{S}}>0 .
\end{gathered}
$$

These inequalities coincide with the second-order conditions in the full alliance and merger cases (i.e., when $\delta=1$ ) and do not exactly match them in the rest of the cases (a similar approach is followed in Brueckner and Proost, 2010). ${ }^{24}$

We can now consider the effect of a change in the scope of alliances on the traffic in the interline and the interhub markets. Totally differentiating (5) and (6) with respect to $q_{S}, q_{H}$, and $\delta$ yields

$$
\begin{aligned}
& \frac{\partial q_{S}}{\partial \delta}=\frac{\overbrace{\frac{\partial \Lambda_{S}}{\partial \delta} \frac{\partial \Lambda_{H}}{\partial q_{H}}}^{>0}+\overbrace{\frac{\partial \Lambda_{S}}{\partial q_{H}} \frac{\partial \Lambda_{H}}{\partial \delta}}^{<0} \underbrace{<0}_{>0}}{\overbrace{<0}^{\Gamma}}, \\
& \frac{\partial q_{H}}{\partial \delta}=\frac{-\overbrace{\frac{\partial \Lambda_{S}}{\partial q_{S}} \frac{\partial \Lambda_{H}}{\partial \delta}}^{<0}+\overbrace{\frac{\partial \Lambda_{S}}{\partial \delta} \frac{\partial \Lambda_{H}}{\partial q_{S}}}^{>0}}{\underbrace{\Gamma}_{>0}},
\end{aligned}
$$

where $\frac{\partial \Lambda_{S}}{\partial \delta}>0$ and $\frac{\partial \Lambda_{H}}{\partial \delta}<0$ by inspection of (5) and (6). Then, the following proposition can be formulated.

Proposition 1 The presence of nonincreasing returns constitutes a sufficient condition ensuring that the effect of deeper alliances on traffic is i) positive in the interline market and ii) negative in the interhub market. 
A rise in the scope of alliances, which implies a deeper revenue sharing between partner airlines, has a different effect in markets $\mathrm{S}$ and $\mathrm{H}$. Since each firm prices monopolistically a complementary input in market $\mathrm{S}$, an increase in $\delta$ can be procompetitive given that it helps internalizing a double marginalization problem. By contrast, it produces anticompetitive effects in market $\mathrm{H}$ where there is network overlap and deeper alliances can relax competition intensity. Proposition 1 shows that these opposing effects are always observed under nonincreasing returns (often implied by the presence of airport congestion) because $C^{\prime \prime} \geqslant 0$ implies that $\frac{\partial \Lambda_{S}}{\partial q_{H}} \leqslant 0$ and $\frac{\partial \Lambda_{H}}{\partial q_{S}} \leqslant 0$, which yield $\frac{\partial q_{S}}{\partial \delta}>0$ and $\frac{\partial q_{H}}{\partial \delta}<0$ (as it can be seen by inspection of (9) and (10)).

However, in the presence of economies of traffic density $\left(C^{\prime \prime}<0\right)$, we observe that $\frac{\partial \Lambda_{S}}{\partial q_{H}}>0$ and $\frac{\partial \Lambda_{H}}{\partial q_{S}}>0$ and, in consequence, the sign of $\frac{\partial q_{S}}{\partial \delta}$ and $\frac{\partial q_{H}}{\partial \delta}$ is ambiguous. The reason is that the described negative effect of deeper alliances in market $\mathrm{H}$ may also generate negative spillovers in market S (as pointed out in Brueckner, 2001). More precisely, under economies of traffic density, a fall in traffic in the interhub market results in a higher marginal cost on the hub-to-hub route. This marginal-cost increase affects both markets and, therefore, can result in higher interhub and interline fares and lower traffic volumes. In such a case, the positive effect in market $\mathrm{S}$ derived from the elimination of a double marginalization externality might be overcome by the negative effect of a marginal-cost increase on the hub-to-hub route. However, the positive effect typically is expected to dominate the negative effect given that, generally, it is observed that there are many interline markets and few interhub markets in the air transportation industry, which implies that a fall in traffic in the interhub market can be easily overcome by a rise of traffic in interline markets. Additionally, carve-outs can be imposed to correct for the possible anticompetitive effects of alliances in interhub markets (further details in Brueckner and Proost, 2010). Therefore, whenever carve-outs are implemented and produce their desired effects, deeper alliances become unequivocally procompetitive. 


\subsection{The effect of joint ventures on traffic}

Our attention shifts now to the effect of a change in the scope of joint ventures on the traffic in both markets. Totally differentiating (5) and (6) with respect to $q_{S}, q_{H}$, and $\mu$ yields

$$
\begin{aligned}
& \frac{\partial q_{S}}{\partial \mu}=\frac{-\overbrace{\frac{\partial \Lambda_{S}}{\partial \mu} \frac{\partial \Lambda_{H}}{\partial q_{H}}}^{?}+\overbrace{\frac{\partial \Lambda_{S}}{\partial q_{H}} \frac{\partial \Lambda_{H}}{\partial \mu}}^{?} \underbrace{\Gamma}_{>0}}{\overbrace{}^{\Gamma}}, \\
& \frac{\partial q_{H}}{\partial \mu}=\frac{-\overbrace{\frac{\partial \Lambda_{S}}{\partial q_{S}} \frac{\partial \Lambda_{H}}{\partial \mu}}^{<0}+\overbrace{\frac{\partial \Lambda_{S}}{\partial \mu} \frac{\partial \Lambda_{H}}{\partial q_{S}}}^{?}}{\underbrace{\Gamma}_{>0}} .
\end{aligned}
$$

From the analysis of these expressions, we obtain the following proposition.

Proposition 2 The presence of increasing returns (economies of traffic density) constitutes a sufficient condition ensuring that the effect of deeper joint ventures on traffic is positive in both markets.

A rise in the scope of joint ventures can produce efficiency gains that yield higher traffic levels, i.e., $\frac{\partial q_{S}}{\partial \mu}>0$ and $\frac{\partial q_{H}}{\partial \mu}>0$. This is always observed in the presence of economies of traffic density $\left(C^{\prime \prime}<0\right)$, where $\frac{\partial \Lambda_{S}}{\partial q_{H}}>0, \frac{\partial \Lambda_{H}}{\partial q_{S}}>0, \frac{\partial \Lambda_{S}}{\partial \mu}>0$, and $\frac{\partial \Lambda_{H}}{\partial \mu}>0$. The reason is that pooling resources by means of cost-sharing agreements leads to a marginal cost reduction, which affects both markets.

When carriers' technology exhibits constant returns $\left(C^{\prime \prime}=0\right)$, cost sharing does not convey any synergy and the effect of $\mu$ vanishes. Therefore, the scope of joint ventures produces no effect on the equilibrium traffic, i.e., $\frac{\partial q_{S}}{\partial \mu}=\frac{\partial q_{H}}{\partial \mu}=0$.

Finally, the pooling of resources implied by deeper joint ventures in the presence of decreasing returns $\left(C^{\prime \prime}>0\right)$ leads to a marginal cost increase, as it is observed in severely congested airports. In this case, the ultimate effect on the equilibrium traffic could be negative. ${ }^{25}$

In the following subsection, we analyze the consumer-welfare-maximizing cooperation agreements in interline and interhub markets, with the ultimate purpose of deriving policy recommendations for antitrust authorities. Later on, the effect of alliances and joint ventures on traffic in interline and interhub markets is tested empirically in Section 6. 


\subsection{Consumer-welfare-maximizing cooperation agreements in inter- line and interhub markets}

As mentioned in Subsection 3.4, the following types of cooperation agreements can be studied: independent firms, soft alliance, full alliance, joint venture, joint venture with full revenue sharing, and merger. We distinguish the following cases: economies of traffic density - weak $\left(C^{\prime \prime}<0\right)$ and strong $\left(C^{\prime \prime}<<0\right)$; constant returns $\left(C^{\prime \prime}=0\right)$; and decreasing returns $\left(C^{\prime \prime}>0\right)$. The analysis that follows identifies the consumer-welfare-maximizing cooperation agreements in markets $\mathrm{S}$ and $\mathrm{H}$ in the relevant $(\mu, \delta)$ space where $0 \leqslant \mu \leqslant \delta \leqslant 1$. The consumer welfare is proxied by quantities $q_{S}$ and $q_{H}{ }^{26}$ In addition, we also indicate the transition between optimal cooperation agreements as $C^{\prime \prime}$ decreases. Proposition 3 below presents the results from the analysis of interline markets.

Proposition 3 Consumer welfare in the interline market is maximized under

i) Full alliance $(\mu=0$ and $\delta=1)$ in the presence of decreasing returns,

ii) Joint venture with full revenue sharing $(\mu \in(0,1)$ and $\delta=1)$ under constant returns,

iii) Merger $(\mu=1$ and $\delta=1)$ in the presence of weak economies of traffic density,

$i v)$ Joint venture or even independent firms $(\mu \in[0,1)$ and $\delta \in[0,1)$ with $\mu \leqslant \delta)$ for strong economies of traffic density.

The proof of this proposition follows three steps. In the first two steps, we analyze the sign of $\frac{\partial q_{S}}{\partial \delta}$ and $\frac{\partial q_{S}}{\partial \mu}$ in expressions (9) and (11), respectively, for every possible value of $C^{\prime \prime}$. In the last step, we identify the pair $(\mu, \delta)$ that yields the maximum $q_{S}$ for every possible value of $C^{\prime \prime}$, noting that each pair $(\mu, \delta)$ corresponds to a particular consumer-welfare-maximizing cooperation agreement. The results obtained in the proposition above are illustrated in Fig. 2, where the arrows indicate the transition between cooperation agreements as $C^{\prime \prime}$ decreases.

In the presence of decreasing returns, the consumer-welfare-maximizing cooperation agreement in market $\mathrm{S}$ is full alliance, i.e., $(\mu, \delta)=(0,1)$. The reason is that decreasing returns ensure a positive effect of $\delta$ on consumer welfare since revenue sharing implies the internalization of a double marginalization externality yielding lower fares and higher traffic volumes (i.e., $\frac{\partial q_{S}}{\partial \delta}>0$ is observed under $C^{\prime \prime}>0$, see Proposition 1). On the other hand, decreasing returns make the pooling of resources inefficient since deeper joint ventures lead to a marginal cost increase that translates into higher fares and lower traffic volumes (i.e., $\frac{\partial q_{S}}{\partial \mu}<0$ is observed under $C^{\prime \prime}>0$, see Proposition 2).

- Insert Fig. 2 about here -

Under constant returns, while the positive effect of $\delta$ on consumer welfare remains unchanged

(i.e., $\frac{\partial q_{S}}{\partial \delta}>0$ is observed under $C^{\prime \prime}=0$ ), the negative effect of $\mu$ vanishes (i.e., $\frac{\partial q_{S}}{\partial \mu}=0$ is 
observed under $C^{\prime \prime}=0$ ). Consequently, the resulting optimal cooperation agreement becomes joint venture with full revenue sharing.

Under weak economies of traffic density, a new adverse cost effect emerges. This effect stems from a fall in traffic in market $\mathrm{H}$, which results in a higher marginal cost on the hub-to-hub route that can result in higher fares and lower traffic volumes in both markets. Consequently, $\delta$ has two effects on $q_{S}$ : a positive effect stemming from the elimination of the double marginalization externality and this new negative cost effect. It turns out that the positive effect overcomes the negative effect under weak economies of traffic density and, therefore, $\frac{\partial q_{S}}{\partial \delta}>0$ is observed under $C^{\prime \prime}<0$. Looking now at the effect of $\mu$, the presence of economies of traffic density yields efficiency gains and, therefore, $\frac{\partial q_{S}}{\partial \mu}>0$ is observed under $C^{\prime \prime}<0$. Thus, the resulting optimal cooperation agreement becomes merger.

Finally, under strong economies of traffic density, the relative weight of the two effects of $\delta$ on $q_{S}$ changes and the negative effect dominates the positive one. Therefore, $\frac{\partial q_{S}}{\partial \delta}<0$ is observed under $C^{\prime \prime}<<0$. On the other hand, the efficiency gains associated with larger values of $\mu$ are reinforced (i.e., $\frac{\partial q_{S}}{\partial \mu}>0$ is observed under $C^{\prime \prime}<<0$ ). Hence, as $\mu \leqslant \delta$, the optimal agreements are now located on the 45-degree line in Fig. 2, which corresponds to joint ventures or even independent firms. The precise location on the 45-degree line depends on the relative strength of these two opposing effects of $\delta$ and $\mu$ on $q_{S}$.

Shifting attention to interhub markets, Proposition 4 below analyzes the consumer-welfaremaximizing cooperation agreement in this case.

Proposition 4 Consumer welfare in the interhub market is maximized under

i) Joint venture or even independent firms $(\mu \in[0,1)$ and $\delta \in[0,1)$ with $\mu \leqslant \delta)$ in the presence of decreasing returns (either weak or strong), constant returns or weak economies of traffic density,

ii) Merger $(\mu=1$ and $\delta=1)$ in the presence of strong economies of traffic density.

The proof of this proposition follows the same procedure as the proof of Proposition 3. The results obtained in Proposition 4 are illustrated in Fig. 3. Again, the arrows indicate the transition between cooperation agreements as $C^{\prime \prime}$ decreases.

In the presence of decreasing returns (typically observed in severely congested airports), deeper alliances are detrimental to consumer welfare (i.e., $\frac{\partial q_{H}}{\partial \delta}<0$ is observed under $C^{\prime \prime}>0$, see Proposition $1 \mathrm{ii}$ )). Consequently, $\delta=0$ and the optimal cooperation agreement is independent firms since $\mu \leqslant \delta$.

As economies of traffic density become stronger, the effect of deeper joint ventures on consumer welfare is increasingly positive because it translates into higher efficiency gains (i.e., $\frac{\partial q_{H}}{\partial \mu}>0$ is observed under $C^{\prime \prime}<0$, see Proposition 2). On the other hand, stronger economies 
of traffic density may also reduce the anticompetitive effect associated with deeper alliances on interhub markets. The reason can be found in the creation of interline traffic that passes through the hub-to-hub route, which may contribute to higher efficiency gains in the presence of economies of traffic density. As a result, deeper joint ventures maximize consumer welfare as economies of traffic density become stronger (i.e., as $C^{\prime \prime}$ decreases), resulting into a merger in the presence of strong economies of traffic density (i.e., $C^{\prime \prime}<<0$ ).

- Insert Fig. 3 about here -

A joint analysis of Figs. 2 and 3 reveals the non-coincidence of optimal cooperation agreements in markets $\mathrm{S}$ and $\mathrm{H}$ for a given $C^{\prime \prime}$. Even more, there is a clear conflict that becomes evident by looking at the diagonal in both figures: joint ventures become deeper as $C^{\prime \prime}$ increases in market $\mathrm{H}$, whereas the opposite occurs in market S. Hence, the socially optimal cooperation agreement will depend on the relative size of these two markets that determines the ultimate net welfare effect. In the section that follows, we elucidate this net welfare effect by means of a numerical simulation.

\section{Consumer-welfare-maximizing cooperation agreements: The net welfare effect}

We perform a numerical analysis to expose the effect of relative market size in markets $\mathrm{S}$ and $\mathrm{H}$ on the overall consumer-welfare-maximizing cooperation agreement. As in Brueckner and Proost (2010), we assume linear forms for the demand and the marginal cost functions, which are given by $D\left(q_{S}\right)=\lambda \alpha-q_{S} / 2, D\left(q_{H}\right)=\alpha-q_{H} / 2$, and $C^{\prime}(q)=1-\theta q$, where $\alpha>0$ denotes market size, $\lambda \geqslant 1$ captures a possible asymmetry in market size, and $\theta \lesseqgtr 0$ stands for the presence and intensity of returns (in terms of our general model, $\theta \lesseqgtr 0$ corresponds to $\left.C^{\prime \prime} \gtreqless 0\right)$. Therefore, economies of traffic density require $\theta>0$. Although our theoretical analysis assumes identical demand functions in markets $\mathrm{S}$ and $\mathrm{H}$, our numerical exercise also allows for asymmetric demands. More specifically, by assuming $\lambda \geqslant 1$, we take account of the fact that market size of interline markets is in general larger than that of interhub markets. ${ }^{27}$

To analyze the effect of the three parameters that appear in the above demand and marginalcost functions, we consider the following feasible region $R$, which is defined as a triple $\{\alpha, \theta, \lambda\}$ where $\alpha \in[4,6], \theta \in[-0.05,0.05]$, and $\lambda \in[1,1.8]$. Any parameter constellation in $R$ ensures positive quantities and marginal costs, along with compliance with second-order conditions (see Appendix B for the details). Given the stylized nature of the considered functional forms, parameter choices are necessarily arbitrary and the analysis is not exhaustive. However, it 
reveals some interesting insights on the effect of the relative market size of markets $\mathrm{S}$ and $\mathrm{H}$ on the overall consumer welfare. The values of $\alpha$ are chosen to ensure positive quantities and fares. Regarding $\theta$, the upper bound is chosen so that second-order conditions are respected and marginal costs are positive (which is common in the related literature) and the lower bound is determined for symmetry considerations. ${ }^{28}$ Finally, the values of $\lambda$ are selected to guarantee a certain variability in the results in terms of consumer-welfare-maximizing cooperation agreements. Figs. 4a and $4 \mathrm{~b}$ display different cases in $R$ allowing to study the effect of variations of the existing parameters on the consumer-welfare-maximizing cooperation agreement. More precisely, we analyze market $\mathrm{S}$ (illustrating the general result in Fig. 2), market $\mathrm{H}$ (illustrating the general result in Fig. 3) and, as a particular added value of this section, the ultimate net welfare effect (denoted CW in Figs. $4 \mathrm{a}$ and $4 \mathrm{~b}$ ) considering both markets altogether. Figs. 4a and $4 \mathrm{~b}$ are plotted in $3 \mathrm{D}$ in the $(\mu, \delta, v)$-space where $v \in\left\{q_{s}, q_{H}, C W\right\}$.

\section{- Insert Figs. 4a and 4b about here -}

\section{$\checkmark$ Effect of market asymmetry $(\lambda)$.}

With $\theta=0$ (i.e., constant returns) and assuming symmetric market sizes (i.e., $\lambda=1$ ), we observe in Figs. 4a and $4 \mathrm{~b}$ that the cooperation agreement maximizing $q_{S}$ is joint venture with full revenue sharing (consistently with Fig. 2), whereas the cooperation agreement maximizing $q_{H}$ is independent firms (consistently with Fig. 3). Looking at the overall impact on consumer welfare (row CW, $\lambda=1$ ), the effect on market $\mathrm{H}$ dominates and, therefore, the socially optimal cooperation agreement is independent firms. Instead, when market $\mathrm{S}$ is substantially larger than market $\mathrm{H}$ (i.e., $\lambda=1.8$ ), the effect in market $\mathrm{S}$ dominates and joint venture with full revenue sharing maximizes consumer welfare (row CW, $\lambda=1.8$ ). Interestingly, for the intermediate case with $\alpha=4$ and $\lambda=1.6$, it can be observed that a joint venture arises.

With $\theta=-0.05$ (i.e., decreasing returns) and $\theta=0.05$ (i.e., economies of traffic density), the effect of a change in $\lambda$ is similar: starting from the symmetric case, as $\lambda$ increases, the socially optimal cooperation agreement shifts from the one that maximizes $q_{H}$ to the one that maximizes $q_{S}$.

$\checkmark$ Effect of market size $(\alpha)$.

Since $\lambda \geqslant 1$, an increase in market size has a larger effect in market $\mathrm{S}$ than in market $\mathrm{H}$. Therefore, increasing $\alpha$ or $\lambda$ produces similar effects. For instance, starting from the case $\{\alpha, \theta, \lambda\}=\{4,0,1.6\}$ where joint venture maximizes consumer welfare, increasing $\alpha$ from 4 to 6 or raising $\lambda$ from 1.6 to 1.8 makes joint venture with full revenue sharing optimal.

$\checkmark$ Effect of intensity of economies of traffic density $(\theta)$.

Concerning market $\mathrm{S}$, the effect of an increase in $\theta$ illustrates the transition between cooperation 
agreements observed in Fig. 2. As $\theta$ rises, the optimal agreement changes first from full alliance to joint venture with full revenue sharing and then to merger.

As for market $\mathrm{H}$, the effect of an increase in $\theta$ depicted in Fig. 3 can also be observed. Larger values of $\theta$ increase the social profitability of deeper joint ventures, even though the optimal agreement remains independent firms for our parameter ranges.

Looking at overall consumer welfare, both the cases with symmetric market sizes (i.e., $\lambda=1$ ) and very asymmetric market sizes (i.e., $\lambda=1.8$ ) yield straightforward results since the optimal agreement is determined by market $\mathrm{H}$ in the former case and by market $\mathrm{S}$ in the latter. However, for intermediate values of market asymmetry, we can observe that the dominance of either market $\mathrm{S}$ or $\mathrm{H}$ depends on the intensity of economies of traffic density.

\section{Empirical application}

In this section, we propose an empirical application to test the effect of different degrees of airline cooperation on traffic. A limitation inherent to our data is related to the impossibility to fully disentangle routes characterized by increasing and decreasing returns. Furthermore, the correlation between revenue and cost-sharing practices may also be high. Hence, the aim of this empirical application is not to provide specific tests of Propositions 1-4, but to examine the impact of cooperation on traffic. Subsamples are used to assess the relevance of increasing and decreasing returns in different contexts.

\subsection{Data and empirical model}

We focus on intercontinental routes characterized by a rich variation in the degree of airline cooperation. More precisely, we consider the transatlantic market (flights from the US and Canada to Europe), the transpacific market (flights from the US and Canada to Eastern Asia and Australasia), and flights from Europe to Eastern Asia and the Middle East. For flights between Europe and the Middle East, we only consider routes longer than 4, 000 kilometers to avoid the inclusion of medium-haul routes in the analysis. Given our focus on intercontinental markets, routes within the US, Canada, Europe, Eastern Asia, Australasia, and Middle-East are not included in the analysis. Data are available from 2010 to 2016 at the quarterly level. We have 16, 897 observations with complete information for all variables. ${ }^{29}$ We only consider routes having non-stop services in several quarters of the considered period.

Our sample includes the four largest world economies (the US, the European Union, China, and Japan), a high proportion of worldwide intercontinental traffic, and most airline cooperation agreements. The unit of observation in our analysis is the pair route-alliance. We define a route 
as a city-pair, so that several airports may be serving the same city-pair in some cases. For example, the city-pair London-New York may include flights from two airports in New York (JFK and Newark) to several airports in London (Heathrow, Gatwick, Stansted, Luton, and London City). We consider jointly the airlines integrated in the three major international alliances (Oneworld, SkyTeam, and Star Alliance). Furthermore, Etihad and Emirates are also identified as separate airlines given their major role in traffic between Europe and Middle East.

Regarding the dependent variable, we use passenger data that come from Official Airlines Guide (OAG). These data include information on local passengers (who fly directly between the two airports) and on connecting passengers. Connecting passenger information is on behind, bridge, and beyond traffic. For example, on the route Atlanta-Frankfurt, behind traffic includes passengers flying from Boston to Frankfurt through Atlanta, beyond traffic includes passengers from Atlanta to Berlin through Frankfurt, and bridge traffic includes passengers with an additional stop in behind or beyond itineraries.

For connecting trips, we restrict the attention to routes between gateways and focus on connecting passengers on these routes. Therefore, the sample could include several segments for one interline trip when the considered routes are longer than 4,000 kilometers. For example, for a Boston to Mumbai trip, the sample could include a Boston-London segment on American Airlines and a London-Mumbai segment on British Airways.

It should be mentioned that our interline observations may contain some online traffic. For example, an Indianapolis-Barcelona two-segment trip operated entirely by American Airlines with a connection in New York, would lead to connecting traffic on the route between New York and Barcelona. Of course, this is not interline but online traffic. Hence, a carrier's connecting traffic on intercontinental routes is likely to contain both interline and online passengers. The interline component of this traffic is expected to be larger when the carrier belongs to a global alliance.

The main explanatory variables in the analysis are the indicators of the degree of airline cooperation, distinguishing between the scope of joint ventures and alliances ( $\mu$ and $\delta$, respectively). While $\mu$ and $\delta$ are considered to be continuous parameters varying in the range $[0,1]$ in the theoretical part, they are defined as binary regressors in the empirical part. More precisely, we consider that $\mu=0$ denotes all cases except joint ventures, for which $\mu=1$. With respect to $\delta$, we consider two alternative approaches:

i) Following the first approach, $\delta=0$ denotes independent firms and soft alliances whereas $\delta=1$ applies to full alliances (which include ATI agreements and equity alliances) and joint ventures (including metal-neutral joint ventures). Therefore, this approach assumes that ATI agreements, equity alliances, and joint ventures are equivalent when it comes to revenue sharing (i.e., in terms of $\delta$ ). 
ii) Following the second approach, $\delta=0$ also includes full alliances whereas $\delta=1$ denotes joint ventures, which implies $\delta=\mu=1$ in the case of joint ventures and 0 otherwise.

An important shortcoming of the first approach is that multicollinearity may prevent us from identifying the joint effect of $\delta$ and $\mu$, given that the correlation between them is very high (the correlation coefficient is 0.84). Differently, multicollinearity is not a problem under the second approach because there is a single cooperation variable in the model. Table 1 provides some examples for existing airline cooperation agreements in intercontinental markets.

- Insert Table 1 about here -

Independent firms denotes those cases where one of the endpoints of the route is not a hub of any airline (e.g., flights of SkyTeam from Atlanta to Barcelona) or where both endpoints are hubs of airlines belonging to different alliances (e.g., flights from Dallas - hub of Oneworld - to Amsterdam - hub of SkyTeam). Soft alliances includes routes whose endpoints are hubs of the same alliance where airline partners cooperate at a basic level, e.g., by means of codesharing agreements or joint frequent-flyer programs (e.g., flights of Oneworld from Chicago to Berlin). As mentioned before, full alliances includes ATI agreements (e.g., between Delta and Czech Airlines on the route New York-Prague) and equity alliances (e.g., between Etihad and Alitalia on the route Rome-Abu Dhabi). Finally, some examples of joint ventures are the agreement between United and ANA on the route Washington-Tokyo or the agreement between Air France and Delta for flights from Atlanta to Paris.

While the theoretical model only considers cooperation agreements with network overlap on the interhub route, our empirical application also allows for the possibility of having just one partner airline operating on this type of routes. ${ }^{30}$ Hence, we define an additional variable $\psi$, that takes value 1 when the route presents no network overlap and 0 when there is an overlap. We also include the interactions $\mu * \psi$ and $\delta * \psi$. The uninteracted coefficients of $\mu$ and $\delta$ provide information on the effect of these variables in the presence of an overlap, while the interaction coefficients show how the absence of an overlap alters this effect.

We estimate a gravity model following the usual practice in the analysis of air transportation demand. Gravity models assume that demand between two endpoints is positively related with the economic and demographic size of these two endpoints and negatively related with the distance between them.

Accordingly, as a first control variable, we include the distance of the non-stop route (Dist), considering its mean value when there are different airport pairs in the same city-pair market. Second, we use the mean population of the origin and destination cities (Pop), which is measured at the urban level. For cities with a population exceeding 300,000 inhabitants, the information is obtained from United Nations (World Urbanization Prospects). The data for smaller cities are 
obtained from the National Statistics Agency of the corresponding country. Third, we include the mean Gross National Income per capita (GNI_pc) and the mean sum of imports and exports over GDP (in \%) of the route's origin and destination countries (Openness), with data obtained from the World Bank (World Development Indicators). Finally, we also incorporate a dummy variable that takes the value 1 for routes between countries that have signed an open skies agreement ( $D^{\text {open_skies }}$ ), including the agreements between the US and the EU (March 2008), Canada and the EU (December 2009), the US and Japan (October 2010), the US and New Zealand (January 1997), the US and Australia (February 2008), the US and Singapore (January 1997), the US and Taiwan (February 1997), the US and Malaysia (June 1997), the US and Korea (April 1998), the US and Indonesia (June 2004), and the US and Thailand (September 2005).

We also include alliance, year, quarter, and city fixed effects. City fixed effects are included separately for both origin and destination cities of the considered routes. Standard errors are clustered at the alliance-route level and are robust to heteroscedasticity.

The empirical model estimates the factors explaining traffic channeled by alliance $a$ on route $k$ in period $t$ (denoted by $Q_{a k t}$ ) as follows

$$
\begin{aligned}
Q_{a k t}= & \alpha+\beta_{1} \delta_{a k t}+\beta_{2} \mu_{a k t}+\beta_{3} \delta_{a k t} * \psi_{\text {akt }}+\beta_{4} \mu_{a k t} * \psi_{a k t}+ \\
& \beta_{5} P_{0 p_{k t}}+\beta_{6} G N I \_p c_{k t}+\beta_{7} \text { Openness } s_{k t}+\beta_{8} D_{i s t_{k t}}+ \\
& \beta_{9} D_{k t}^{\text {open_skies }}+\gamma_{\text {alliance }}^{\prime}+\eta_{\text {year }}^{\prime}+\rho_{\text {quarter }}^{\prime}+ \\
& \lambda_{\text {airport_origin }}^{\prime}+\lambda^{\prime}{ }_{\text {airport_destination }}+\varepsilon_{\text {akt }},
\end{aligned}
$$

where all continuous variables are expressed in logarithms.

Initially, we run regressions using the entire sample and a subsample including only transatlantic routes. With these regressions, we can examine the impact of deeper degrees of airline cooperation on traffic in the intercontinental aviation market from a general perspective. Note that the transatlantic subsample has much more variability than any other geographical market in terms of our main explanatory variables ( $\mu$ and $\delta$ ).

As we have mentioned above, a limitation of our data lies in the difficulty of disentangling routes characterized by increasing and decreasing returns. Hence, we also look at different subsamples that may exhibit differences in terms of returns. In such a way, the impact of deeper degrees of airline cooperation on traffic can be explained by the predominance of a certain type of returns. More precisely, we consider a subsample comprising routes with traffic volume within the lowest $25 \%$ percentile; a subsample consisting of routes with traffic volume within the highest $25 \%$ percentile; and, finally, a subsample containing routes originated in an airport registering a congestion level within the highest $25 \%$ percentile. Our indicator of congestion is the average 
delay per flight (expressed in minutes) at the origin airport. These data on congested routes are only available for routes departing from US airports. ${ }^{31}$ We make use of these subsamples to assess the relevance of increasing and decreasing returns. In principle, decreasing returns should be expected on dense and congested routes, whereas thin routes should have a higher potential to exploit economies of traffic density. However, note that traffic density could also indicate a higher potential to increase traffic. In such a case, dense routes would exhibit increasing returns. Consequently, we need to be cautious in the interpretation of our results in this respect.

\subsection{Results}

Tables 2 and 3 show the results for the sample of interhub and interline routes, respectively. The full sample is considered in the first and the second regressions (columns I and II), while the third and the fourth restrict the attention to the transatlantic market (columns III and IV). The results in columns V and VI focus on the thinnest routes, while columns VII and VIII show the regressions for the densest routes. Finally, results in columns IX and X consider the routes departing from the most congested US airports.

As mentioned above, we implement two alternative approaches in the classification of cooperation agreements, where the value $\delta=1$ denotes full alliances and joint ventures under the first approach, whereas it is limited to joint ventures under the second approach. Given that the continuous variables are expressed in logarithms, the coefficients can be interpreted as elasticities.

\section{- Insert Tables 2 and 3 about here -}

Regarding the controls, the coefficient of the Dist variable is generally negative and statistically significant for both the interhub and the interline markets. By contrast, the coefficients of the variables Pop, GNI_pc, and Openness are generally not significant. A possible explanation is that their effect could already be captured by the time and city fixed effects. In a similar vein, the coefficient of the $D^{\text {open_skies }}$ variable is not statistically significant in most regressions. However, it is interesting to mention that this coefficient is positive and statistically significant for the subsample of thinnest routes in interline markets (columns V and VI in Table 3) and negative and statistically significant for the subsample of routes departing from congested US airports in interhub markets (columns IX and X in Table 2). Such a result provides some partial evidence suggesting that open skies agreements could lead to some redistribution of traffic from the densest to the thinnest routes.

Looking at our main explanatory variables, we find an increase of traffic associated with stronger levels of cooperation. This is true for all the considered subsamples and could be related to the presence of economies of traffic density in the intercontinental airline market. 
Under the first approach (odd columns in Tables 2 and 3), we find clear evidence suggesting that deeper revenue sharing leads to more traffic, both for interhub and interline markets since the $\delta$-coefficient is positive and statistically significant in all regressions, except for the subsample of densest routes (column VII in both tables) where the variable is positive but statistically insignificant (although the magnitude of the effect is still high). The magnitude of the effect is particularly high for the transatlantic market (column III in both tables), and similar in all other cases. The coefficient of the interaction variable $\delta * \psi$ is always negative and, in most cases, statistically significant. It can be observed that the magnitude of this negative effect is lower than the positive one derived from the uninteracted $\delta$ variable. Thus, the overlap effect partly offsets the positive effect without reversing it.

Still under the first approach, the coefficient of the uninteracted $\mu$ variable is negative in all regressions although it is not statistically significant (both for interhub and interline markets), except for the subsample of routes departing from congested US airports (column IX in both tables). Therefore, deeper cost sharing with network overlap does not lead to more traffic as compared to pure revenue sharing. In other words, the positive effect of joint ventures on traffic is fully captured by $\delta$. The coefficient of the interaction variable $\mu * \psi$ is generally positive and, for some of the considered subsamples, statistically significant. The magnitude of this effect is higher than that of the coefficient of the uninteracted $\mu$. Consequently, deeper cost sharing without network overlap generates additional traffic.

The second approach (even columns in Tables 2 and 3) contemplates a single cooperation variable that rules out the potential multicollinearity problem related to the first approach and allows isolating the effect of joint ventures. Under this specification, we find that deeper joint ventures unequivocally create traffic. The coefficient of the uninteracted $\mu$ variable (which is equal to $\delta$ under this approach) is positive and statistically significant both for interhub and interline markets, except for the subsample of densest routes in interline markets (column VIII in Table 3), although the scale of the effect is still remarkable. The magnitude of the coefficient is particularly high for the transatlantic market and for the subsample of routes departing from congested US airports (columns IV and X in both tables). Finally, the interaction variable $\mu * \psi$ is not statistically different from zero in any regression and, therefore, the difference in significance between joint ventures with and without network overlap cannot be confirmed.

Taking into account Propositions 1 and 2, we can relate our empirical results with our theoretical predictions by stressing the relevance of economies of traffic density in the considered subsamples. Proposition 1 states that the presence of nonincreasing returns constitutes a sufficient condition ensuring that the effect of deeper alliances on traffic is positive in interline markets and negative in interhub markets. Under economies of traffic density, although the result is ambiguous (because a fall in traffic in interhub markets could also affect interline markets 
through a marginal-cost increase on hub-to-hub routes), a positive effect should be expected given that the number of interline markets typically exceeds that of interhub markets (this is a stylized fact in the air transportation industry). Our empirical results confirm this positive effect. Proposition 2 states that the presence of increasing returns constitutes a sufficient condition ensuring the positive effect of deeper joint ventures on traffic in both markets. Again, our empirical results confirm this positive effect.

All in all, the results of our empirical application show that deeper degrees of airline cooperation (revenue and cost sharing) have a positive impact on traffic both in interline and interhub markets. While these results are in general consistent with the existence of economies of traffic density, they also suggest that deeper alliances and joint ventures may also have a positive impact on traffic under decreasing returns (typically observed in severely congested airports). Therefore, the potential anticompetitive effect of deeper alliances in interhub markets is not observed in our sample of intercontinental routes for the period 2010-2016. ${ }^{32}$

\section{Concluding remarks}

In this paper we have analyzed the effect of different cooperation agreements on consumer welfare in the air transportation market. This is the first study that proposes a unified framework to model a wide-range of cooperation agreements such as soft alliances, full alliances, joint ventures, joint ventures with full revenue sharing, and mergers. It also analyzes the impact of these agreements on consumer welfare in interhub and interline markets for different cost technologies, from economies of traffic density to decreasing returns (often caused by airport congestion). We find that the socially optimal cooperation agreement in interhub and interline markets typically does not coincide and we elucidate the ultimate net welfare effect taking into account market size asymmetry between interhub and interline markets. Our empirical application shows that deeper degrees of airline cooperation lead to more traffic both in interhub and interline markets, which may be consistent with the dominance of economies of traffic density in intercontinental routes. Moreover, the presence of decreasing returns (typically observed in severely congested airports) does not seem to affect this positive effect of airline cooperation on traffic.

The results of this paper have relevant policy implications. More precisely, the potential anticompetitive effect of deeper alliances in interhub markets is not confirmed empirically (even in the presence of decreasing returns). In the light of this result, we conclude that carve-outs do not seem to be needed on intercontinental routes. Cost-sharing agreements (joint ventures) under economies of traffic density are in nature positive since they translate into efficiency gains. Additionally, no potential anticompetitive effect associated with deeper joint ventures 
under decreasing returns is observed empirically. Therefore, these agreements should be clearly favored at the intercontinental level as long as they are not used as a subterfuge to sustain other anticompetitive practices.

The results in this paper suggest some avenues for future research. First, the effect of hybrid cooperation agreements could be tested in other network industries, such as telecommunications, industrial distribution, data vault, postal services or computer networks. Second, hybrid cooperation agreements under the form of equity alliances (by means of cross-ownership participations) are nowadays a common feature in many industries (such as the pharmaceutical or the automotive industries), where they coexist with other cooperation agreements (such as joint ventures). Our unified framework could also be adapted to assess their final effect on consumer welfare.

\section{Acknowledgements}

We are indebted to Jan K. Brueckner for providing many relevant suggestions that have led to a substantial improvement in the paper. We are grateful to two anonymous referees for their detailed comments and suggestions. We are also thankful for the comments received during the Workshop on Air Transport at Universitat de Barcelona, the 1st Catalan Economic Society Conference, and the ITEA Annual Conference 2017. We acknowledge financial support from the Spanish Ministry of Economy and Competitiveness (ECO2016-75410-P, ECO2013-42884-P) and Generalitat de Catalunya (2014SGR631). 


\section{References}

[1] Baker, G.P., Gibbons R., Murphy, K.J., 2008. Strategic alliances: Bridges between 'islands of conscious power'. Journal of the Japanese and International Economies 22, 146-163.

[2] Bilotkach, V., 2005. Price competition between international airline alliances. Journal of Transport Economics and Policy 39, 167-190.

[3] Bilotkach, V., 2011. Multimarket contact and intensity of competition: Evidence from an airline merger. Review of Industrial Organization 38, 95-115.

[4] Bilotkach, V., Hüschelrath, K., 2013. Airline alliances, antitrust immunity, and market foreclosure. Review of Economics and Statistics 95 (4), 1368-1385.

[5] Bilotkach, V., Fageda, X., Flores-Fillol, R., 2013. Airline consolidation and the distribution of traffic between primary and secondary hubs. Regional Science and Urban Economics 43 (6), 951-963.

[6] Borenstein, S., 1990. Airline mergers, airport dominance, and market power. American Economic Review Papers and Proceedings 80, 400-404.

[7] Brueckner, J.K., 2001. The economics of international codesharing: An analysis of airline alliances. International Journal of Industrial Organization 19, 1475-1498.

[8] Brueckner, J.K., 2003. International airfares in the age of alliances: The effects of codesharing and antitrust immunity. Review of Economics and Statistics 85 (1), 105-118.

[9] Brueckner, J.K., Whalen, W.T., 2000. The price effects of international airline alliances. The Journal of Law and Economics 43 (2), 503-545.

[10] Brueckner, J.K., Proost, S., 2010. Carve-outs under airline antitrust immunity. International Journal of Industrial Organization 28, 657-668.

[11] Brueckner, J.K., Spiller, P.T., 1991. Competition and mergers in airline networks. International Journal of Industrial Organization 9, 323-342.

[12] Brueckner, J.K, Lee, D., Singer, E., 2011. Alliances, codesharing, antitrust immunity and international airfares: Do previous patterns persist? Journal of Competition Law and Economics 7, 573-602. 
[13] Calzaretta, R.J., Eilat, Y., Israel, M.A., 2017. Airline cooperation and international travel: Analyses of the impact of antitrust immunity and joint ventures on fares and traffic. Working Paper. Available at SSRN: https://ssrn.com/abstract=2921941 or http://dx.doi.org/10.2139/ssrn.2921941.

[14] Fageda, X., Perdiguero, J., 2014. An empirical analysis of a merger between a network and low-cost airlines. Journal of Transport Economics and Policy 48, 81-96.

[15] Flores-Fillol, R., Moner-Colonques, R., 2007. Strategic formation of airline alliances. Journal of Transport Economics and Policy 41 (3), 427-449.

[16] Gayle, P.G., Thomas, T., 2016. Assessing firm behavior in carve-out markets: Evidence on the impact of carve-out policy. Journal of Economic Behavior and Organization 128, 178-194.

[17] Gibbons R., 2005. Four formal(izable) theories of the firm? Journal of Economic Behavior and Organization 58, 200-245.

[18] Gillespie, W., Richard, O., 2012. Antitrust immunity grants to joint venture agreements: Evidence from international airline alliances. Antitrust Law Journal 78 (2), 443-469.

[19] Hassin, O., Shy, O., 2004. Code-sharing agreements and interconnections in markets for international flights. Review of International Economics 12, 337-352.

[20] Heimer, O., Shy O., 2006. Code-sharing agreements, frequency of flights, and profits under parallel operation, in Lee, D. (ed.) Advances in Airline Economics, vol. 1, Elsevier, Amsterdam.

[21] Kim, E.H., Singal , V., 1993. Mergers and market power: Evidence from the airline industry. American Economic Review 83, 549-569.

[22] Kwoka, J., Shumilkina, E., 2010. The price effect of eliminating potential competition: Evidence from an airline merger. Journal of Industrial Economics 58, 767-793.

[23] Lopez, A.L., Vives, X., 2016. Cross-ownership, R\&D spillovers, and antitrust policy. IESE, WP-1140-E, 05/2016.

[24] Luo, D., 2014. The price effects of the Delta/Northwest airline merger. Review of Industrial Organization 44 (1), 27-48.

[25] Menard, C., 2004. The economics of hybrid organizations. Journal of Institutional and Theoretical Economics 160, 1-32. 
[26] Oum, T.H., Park, J.H., Zhang, A., 1996. The effects of airline codesharing agreements on firm conduct and international air fares. Journal of Transport Economics and Policy 30, 187-202.

[27] Park, J.H., 1997. The effects of airline alliances on markets and economic welfare. Transportation Research Part E 33, 181-95.

[28] Park, J.H., Zhang, A., 1998. Airline alliances and partner firms' output. Transportation Research Part E 34, 245-255.

[29] Shen, Y., 2017. Market competition and market price: Evidence from United/Continental airline merger. Economics of Transportation 10, 1-7.

[30] Thomas, J., Catling, B., 2014. Reaching new heights together: How airlines can maximize the value of joint ventures. L.E.K. Executive Insights, vol. XVI (4), 1-5.

[31] Whalen, W.T., 2007. A panel data analysis of code-sharing, antitrust immunity, and open skies treaties in international aviation markets. Review of Industrial Organization 30, 39-61.

[32] Williamson, O.E., 1985. Economic institutions of capitalism. The Free Press-Macmillan, New York.

[33] Williamson,O.E., 1996. The mechanisms of governance. Oxford University Press, New York.

[34] Zhang A., Zhang, Y., 2006. Rivalry between strategic alliances. International Journal of Industrial Organization 24, 287-301.

\section{Notes}

\footnotetext{
${ }^{1}$ Hybrid cooperation agreements are also a widespread and well-known phenomenon in other industries such as pharmaceuticals, biotechnology, medical devices, and telecommunications, where 'firms have invented far more ways to work together than organizational economics has so far expressed, not to mention evaluated' (Baker et al., 2008). Menard (2004) has used the term hybrid forms of government structure to refer to this kind of cooperation agreements (see also Williamson, 1985 and 1996).

${ }^{2}$ An exception is the European aviation market that works as a domestic market since 1997.

${ }^{3}$ Looking at current practices, it might be argued that ATI alliances do not imply revenue sharing. However, they imply a close coordination in setting fares and are used to maximize joint profits on certain routes.

${ }^{4}$ In the US, a necessary step to make a joint venture effective is to get ATI from the corresponding competition authority.

${ }^{5}$ Thereby, we take airlines' decision of choosing a particular cooperation agreement as given. For an analysis of the rationale behind this decision, see, for example, Menard (2004) and Gibbons (2005).
} 
${ }^{6}$ Other theoretical studies on alliances are Park (1997), Hassin and Shy (2004), Bilotkach (2005), Zhang and Zhang (2006), and Heimer and Shy (2006).

${ }^{7}$ The study of Calzaretta et al. (2017) is the only study that separates the effects of ATI agreements and joint ventures. They find additional fare reductions associated to joint ventures as compared to ATI agreements. Their results also suggest that two-partner joint ventures do not imply an increase in fares on non-stop routes with network overlap. However, they do not control for traffic in their fare regressions.

${ }^{8}$ Brueckner (2001) proposes a model to study the effects of airline alliances under constant returns by considering a positive demand in every potential city-pair market. He concludes that the relevant effects occur in the interhub and interline markets. Consequently, Brueckner and Proost (2010) focus on these two markets by assuming no market demand in the remaining potential markets. We follow this approach because it yields a more tractable setting that allows studying more sophisticated cooperation agreements and cost technologies.

${ }^{9}$ Relaxing this simplifying assumption would introduce asymmetries into the analysis since airlines would need to set two different partial prices for passengers located in $S_{1 k}$ and $S_{2 \ell}$. While this would make the analysis substantially more cumbersome, it would not offer any additional insight.

${ }^{10}$ Notice that $d(\cdot)$ denotes the aggregate demand in all interline markets. Thus, in the case that spokes have the same number of consumers, demand in each interline market is $d(\cdot) / 2 K L$, where the 2 factor reflects that trips can be initiated at either $S_{1 k}$ or $S_{2 \ell}$.

${ }^{11}$ While choosing either prices or quantities is equivalent in market $\mathrm{S}$ (since there are two local monopolies), the existence of a composite good implies having partial prices (i.e, subfares) as firms' choice variables.

${ }^{12}$ This functional form can be rationalized assuming cost minimization under commonly used production technologies, such as general CES technologies of the form $Q=A\left[\sum_{m=1}^{M} \beta_{m} x_{m}^{\rho}\right]^{\epsilon / \rho}$, where $Q$ is total output, $x_{m}$ is input $m, \epsilon>0$ denotes the returns-to-scale parameter, $A>0,0<\beta_{m}<1$, and $\rho \leqslant 1$. The case $\epsilon<1$ indicates decreasing returns, $\epsilon=1$ constant returns, and $\epsilon>1$ increasing returns. With these technologies, minimization of production costs $\sum_{m=1}^{M} C_{m}=\sum_{m=1}^{M} r_{m} x_{m}$, where $r_{m}$ denotes the price of cost component $m$, gives rise to conditional input demand functions given by $x_{m}=f_{m}\left(r_{1}, \ldots, r_{M}\right) Q^{1 / \epsilon}$. Therefore, the resulting cost function is $\sum_{m=1}^{M} C_{m}=\sum_{m=1}^{M} a_{m} Q^{1 / \epsilon}=Q^{1 / \epsilon}$, with $a_{m}=r_{m} f_{m}\left(r_{1}, \ldots, r_{M}\right)$ (and normalizing $\sum_{m=1}^{M} a_{m}=1$ ). As it can be observed, $\sum_{m=1}^{M} C_{m}=C[Q]=Q^{1 / \epsilon}$, implying that all cost components are evaluated at the same output level and inherit symmetrically the returns to scale exhibited by the production function.

${ }^{13}$ In a symmetric equilibrium, we have $q_{S}^{i}=q_{S} / 2$ and $q_{H}^{i}=q_{H} / 2$.

${ }^{14}$ The distinction between $C_{H H}^{i}=C\left[q_{S}^{i}+q_{H}^{j}\right]$ and $C_{H H}^{i}=C\left[q_{S}+q_{H}\right] / 2$ is the key element to model cost synergies in Brueckner and Proost (2010).

${ }^{15}$ An alternative way of modeling joint ventures would be to assume that they involve a certain share $\mu$ of total traffic on the $h u b$-to- $h u b$ route. In such a case, airline $i$ 's cost would become $C_{H H}^{i}=C\left[(1-\mu)\left(q_{S}^{i}+q_{H}^{i}\right)\right]+$ $C\left[\mu\left(q_{S}+q_{H}\right)\right] / 2$. Notice that both approaches are equivalent in the case of constant returns.

${ }^{16}$ The main results of our analysis do not depend on this assumption. However, assuming a limit in the convexity of the cost function under decreasing returns allows ruling out an empirically irrelevant case and renders the analysis more tractable.

${ }^{17}$ Notice that, when carriers' technology exhibits constant returns, the effect of $\mu$ vanishes because $C\left[q_{S}+q_{H}\right] / 2=$ $C\left[\left(q_{S}+q_{H}\right) / 2\right]$ and $(2)$ becomes $C^{i}=C\left[q_{S}\right]-C\left[q_{S}^{i}+q_{H}^{i}\right]$.

${ }^{18} \mathrm{~A}$ similar approach is followed in Zhang and Zhang (2006).

${ }^{19}$ Cross-equity agreements are labeled as revenue-sharing agreements (and not profit-sharing agreements) to 
emphasize the fact that they do not imply any kind of cost-sharing. More precisely, even in the case of a full alliance (i.e., $\mu=0, \delta=1$ ), where $\Pi^{i}=\pi^{i}+\pi^{j}=R^{i}+R^{j}-C^{i}-C^{j}$, no cost synergies from pooling resources would be exploited (the two cost terms are independent). Differently, in the case of a merger (i.e., $\mu=1, \delta=1$ ), we would have revenue sharing and a single cost term, meaning that cost synergies are exploited.

${ }^{20}$ It could be argued that cost-sharing agreements under decreasing returns may be unnatural. However, it makes sense to include this possibility because they are commonly observed in reality since joint ventures (and especially mergers) between airlines involve many routes characterized by different types of returns. In addition, joint ventures also imply revenue sharing (i.e., $\mu \leqslant \delta$ ). Therefore, even if there are negative effects stemming from cost sharing agreements under decreasing returns, such effects could be overcome by the positive ones implied by revenue sharing. Finally, it should be noticed that we are not studying the equilibrium in the formation of airline cooperation agreements but the effect of such potential agreements on consumer welfare.

${ }^{21}$ In this case, airline $i$ 's profit in (4) would become

$$
\begin{aligned}
\Pi^{i}= & \underbrace{\left\{p_{S}^{i} d\left(p_{S}^{i}+p_{S}^{j}\right)+D\left(q_{H}^{i}+q_{H}^{j}\right) q_{H}^{i}-C\left[q_{S}\right]-\mu C\left[q_{S}+q_{H}\right] / 2-(1-\mu) C\left[q_{S}^{i}+q_{H}^{i}\right]\right\}}_{\pi^{i}} \\
& +\underbrace{\delta\left\{p_{S}^{j} d\left(p_{S}^{i}+p_{S}^{j}\right)+\gamma D\left(q_{H}^{i}+q_{H}^{j}\right) q_{H}^{j}-C\left[q_{S}\right]-\mu C\left[q_{S}+q_{H}\right] / 2-(1-\mu) C\left[q_{S}^{i}+q_{H}^{i}\right]\right\}}_{\pi^{j}} .
\end{aligned}
$$

${ }^{22}$ More recently, Gayle and Thomas (2016) analyze the effect of carve-outs using data from international air travel where at least one segment on the itinerary is operated by a US carrier. They conclude that carve-outs may not be effective in preventing airline cooperation in practice.

${ }^{23}$ More information is available from the authors on request.

${ }^{24}$ The sufficient conditions that ensure $\frac{\partial \Lambda_{S}}{\partial q_{S}}<0, \frac{\partial \Lambda_{H}}{\partial q_{H}}<0$, and $\Gamma>0$ are available from the authors on request. The general second-order conditions, which can be computed from $\frac{\partial^{2} \Pi^{i}}{\partial\left(p_{S}^{i}\right)^{2}}, \frac{\partial^{2} \Pi^{i}}{\partial\left(q_{H}^{i}\right)^{2}}$, and $\frac{\partial^{2} \Pi^{i}}{\partial\left(p_{S}^{i}\right) \partial\left(q_{H}^{i}\right)}$, are also available from the authors on request. As explained in Section 5, with linear expressions for demand and marginal cost, an upper bound on the intensity of economies of traffic density is required to ensure compliance with second-order conditions and positivity of marginal costs.

${ }^{25}$ Generally, in this case, the sign of $\frac{\partial q_{S}}{\partial \mu}$ and $\frac{\partial q_{H}}{\partial \mu}$ is ambiguous since $\frac{\partial \Lambda_{S}}{\partial q_{H}}<0, \frac{\partial \Lambda_{H}}{\partial q_{S}}<0, \frac{\partial \Lambda_{S}}{\partial \mu}<0$, and $\frac{\partial \Lambda_{H}}{\partial \mu}<0$.

${ }^{26}$ With linear demand functions (which are used in Section 5), comparing consumer welfare and quantities is tantamount.

${ }^{27}$ Looking at the data used in our empirical application in Section 6 (Marketing Information Data Tapes data for a sample of intercontinental markets), we observe that connecting traffic is larger than local traffic for 60 percent of the routes (more information available from authors on request).

${ }^{28}$ See, for instance, Brueckner and Spiller (1991), Brueckner (2001), and Brueckner and Proost (2010).

${ }^{29}$ Note that the main joint venture agreements in the transatlantic market took place in the beginning of the considered period or even before. This is a limitation of our data as we cannot evaluate changes before and after the joint ventures in the biggest market of our sample.

${ }^{30}$ Although our theoretical model does not apply to the case where just one partner airline operates on the interhub route, it captures in a simple way the basic tradeoffs related to the effect of airline cooperation agreements in interline and interhub markets.

${ }^{31}$ Information available from the US Department of Transportation (see https://www.bts.gov/). 
${ }^{32}$ This result is in line with Oum et al. (1996), Park and Zhang (1998), Brueckner and Whalen (2000), and Bilotkach and Hüschelrath (2013). 


\section{A Appendix: Proofs}

Proof of Proposition 1. Notice that

$$
\begin{aligned}
\frac{\partial \Lambda_{S}}{\partial q_{H}} & =-\frac{1-\mu}{2} C^{\prime \prime}\left[\frac{q_{S}+q_{H}}{2}\right]-\mu C^{\prime \prime}\left[q_{S}+q_{H}\right] \text { and } \\
\frac{\partial \Lambda_{H}}{\partial q_{S}} & =-\frac{1-\mu}{2} C^{\prime \prime}\left[\frac{q_{S}+q_{H}}{2}\right]-\frac{(1+\delta) \mu}{2} C^{\prime \prime}\left[q_{S}+q_{H}\right]
\end{aligned}
$$

Thus, $C^{\prime \prime} \geqslant 0$ implies that $\frac{\partial \Lambda_{S}}{\partial q_{H}} \leqslant 0$ and $\frac{\partial \Lambda_{H}}{\partial q_{S}} \leqslant 0$. Therefore, $\frac{\partial q_{S}}{\partial \delta}>0$ and $\frac{\partial q_{H}}{\partial \delta}<0$ follow immediately as both terms in the numerator of (9) are non-negative and both terms in the numerator of (10) are non-positive.

Proof of Proposition 2. Notice that

$$
\begin{aligned}
\frac{\partial \Lambda_{S}}{\partial \mu} & =C^{\prime}\left[\frac{q_{S}+q_{H}}{2}\right]-C^{\prime}\left[q_{S}+q_{H}\right] \\
\frac{\partial \Lambda_{H}}{\partial \mu} & =C^{\prime}\left[\frac{q_{S}+q_{H}}{2}\right]-(1+\delta) \frac{C^{\prime}\left[q_{S}+q_{H}\right]}{2} .
\end{aligned}
$$

Thus, from inspection of (A1)-(A4), $C^{\prime \prime}<0$ implies that $\frac{\partial \Lambda_{S}}{\partial \mu}>0, \frac{\partial \Lambda_{H}}{\partial \mu}>0, \frac{\partial \Lambda_{S}}{\partial q_{H}}>0$, and $\frac{\partial \Lambda_{H}}{\partial q_{S}}>0$. Therefore, $\frac{\partial q_{S}}{\partial \mu}>0$ and $\frac{\partial q_{H}}{\partial \mu}>0$ follow immediately as both terms in the numerators of (11) and (12) are positive.

\section{Proof of Proposition 3.}

Effect $\delta$ on $q_{S}$. From (9) we observe that the effect of $\delta$ on $q_{S}$ depends on the sign and size of $\frac{\partial \Lambda_{S}}{\partial q_{H}}=-\frac{1-\mu}{2} C^{\prime \prime}\left[\frac{q_{S}+q_{H}}{2}\right]-\mu C^{\prime \prime}\left[q_{S}+q_{H}\right]$ (expression (A1)) as we know that $\frac{\partial \Lambda_{S}}{\partial \delta}>0$ and $\frac{\partial \Lambda_{H}}{\partial \delta}<0$ by inspection of (5) and (6) and $\frac{\partial \Lambda_{H}}{\partial q_{H}}<0$ is assumed in (7). Thus,

i) for $C^{\prime \prime}>0$, then $\frac{\partial q_{S}}{\partial \delta}>0$ as $\frac{\partial \Lambda_{S}}{\partial q_{H}}<0$,

ii) for $C^{\prime \prime}=0$, then $\frac{\partial q_{S}}{\partial \delta}>0$ as $\frac{\partial \Lambda_{S}}{\partial q_{H}}=0$,

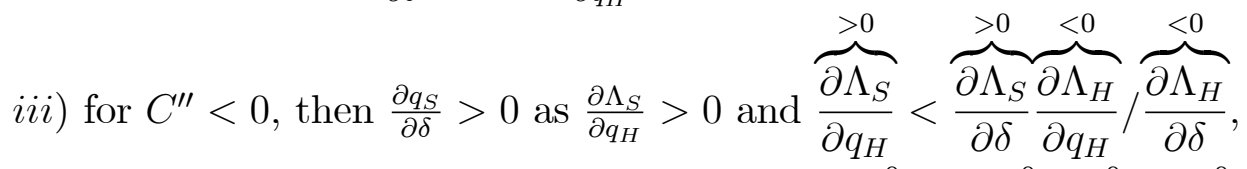

$i v$ ) for $C^{\prime \prime}<<0$, then $\frac{\partial q_{S}}{\partial \delta}<0$ as $\frac{\partial \Lambda_{S}}{\partial q_{H}}>0$ and $\overbrace{\frac{\partial \Lambda_{S}}{\partial q_{H}}}^{>0}>\overbrace{\frac{\partial \Lambda_{S}}{\partial \delta} \frac{\partial \Lambda_{H}}{\partial q_{H}}}^{>0} \overbrace{\frac{\partial \Lambda_{H}}{\partial \delta}}^{<0}$.

Effect $\mu$ on $q_{S}$. From (11) we observe that the effect of $\mu$ on $q_{S}$ depends on the sign of $\frac{\partial \Lambda_{S}}{\partial \mu}=C^{\prime}\left[\frac{q_{S}+q_{H}}{2}\right]-C^{\prime}\left[q_{S}+q_{H}\right], \frac{\partial \Lambda_{S}}{\partial q_{H}}=-\frac{1-\mu}{2} C^{\prime \prime}\left[\frac{q_{S}+q_{H}}{2}\right]-\mu C^{\prime \prime}\left[q_{S}+q_{H}\right]$ (expression (A1)), and $\frac{\partial \Lambda_{H}}{\partial \mu}=C^{\prime}\left[\frac{q_{S}+q_{H}}{2}\right]-(1+\delta) \frac{C^{\prime}\left[q_{S}+q_{H}\right]}{2}$, as $\frac{\partial \Lambda_{H}}{\partial q_{H}}<0$ is assumed in (7). Thus,

$i)$ for $C^{\prime \prime}>0$, then $\frac{\partial q_{S}}{\partial \mu}<0$ as $\frac{\partial \Lambda_{S}}{\partial \mu}<0$, $\frac{\partial \Lambda_{S}}{\partial q_{H}}<0$, and $\frac{\partial \Lambda_{H}}{\partial \mu}>0$ since $C^{\prime}\left[\frac{q_{S}+q_{H}}{2}\right]>\frac{C^{\prime}\left[q_{S}+q_{H}\right]}{2}$ is assumed, 
ii) for $C^{\prime \prime}=0$, then $\frac{\partial q_{S}}{\partial \mu}=0$ as $\frac{\partial \Lambda_{S}}{\partial \mu}=0, \frac{\partial \Lambda_{S}}{\partial q_{H}}=0$, and $\frac{\partial \Lambda_{H}}{\partial \mu}>0$, iii) for $C^{\prime \prime}<0$, then $\frac{\partial q_{S}}{\partial \mu}>0$ as $\frac{\partial \Lambda_{S}}{\partial \mu}>0, \frac{\partial \Lambda_{S}}{\partial q_{H}}>0$, and $\frac{\partial \Lambda_{H}}{\partial \mu}>0$, $i v)$ for $C^{\prime \prime}<<0$, then $\frac{\partial q_{S}}{\partial \mu}>0$ as $\frac{\partial \Lambda_{S}}{\partial \mu}>0, \frac{\partial \Lambda_{S}}{\partial q_{H}}>0$, and $\frac{\partial \Lambda_{H}}{\partial \mu}>0$.

In conclusion,

i) $(\mu, \delta)=(0,1)$ for $C^{\prime \prime}>0$,

ii) $(\mu, \delta)=(\mu, 1)$ with $\mu \in(0,1)$ for $C^{\prime \prime}=0$,

iii) $(\mu, \delta)=(1,1)$ for $C^{\prime \prime}<0$,

iv) $(\mu, \delta)=(\delta, \delta)$ with $\delta \in[0,1)$ for $C^{\prime \prime}<<0$, because $\frac{\partial q_{S}}{\partial \delta}<0$ and $\frac{\partial q_{S}}{\partial \mu}>0$ implies that constraint $\mu \leqslant \delta$ becomes binding.

\section{Proof of Proposition 4.}

Effect $\delta$ on $q_{H}$. From (10) we observe that the effect of $\delta$ on $q_{H}$ depends on the sign and size of $\frac{\partial \Lambda_{H}}{\partial q_{S}}=-\frac{1-\mu}{2} C^{\prime \prime}\left[\frac{q_{S}+q_{H}}{2}\right]-\frac{(1+\delta) \mu}{2} C^{\prime \prime}\left[q_{S}+q_{H}\right]$ (expression (A2)) as we know that $\frac{\partial \Lambda_{S}}{\partial \delta}>0$ and $\frac{\partial \Lambda_{H}}{\partial \delta}<0$ by inspection of (5) and (6) and $\frac{\partial \Lambda_{S}}{\partial q_{S}}<0$ is assumed in (7). Thus,

i) for

$\checkmark C^{\prime \prime}>0$, then $\frac{\partial q_{H}}{\partial \delta}<0$ (which implies $\delta=0$ ) as $\frac{\partial \Lambda_{H}}{\partial q_{S}}<0$,

$\diamond C^{\prime \prime}=0$, then $\frac{\partial q_{H}}{\partial \delta}<0$ as $\frac{\partial \Lambda_{H}}{\partial q_{S}}=0$,

$\diamond C^{\prime \prime}<0$, then $\frac{\partial q_{H}}{\partial \delta}<0$ as $\frac{\partial \Lambda_{H}}{\partial q_{S}}>0$ and $\frac{\partial \Lambda_{H}}{\partial q_{S}}<\overbrace{\frac{\partial \Lambda_{S}}{\partial q_{S}} \frac{\partial \Lambda_{H}}{\partial \delta}}^{<0} / \frac{\overbrace{\frac{\partial \Lambda_{S}}{\partial \delta}}^{>0}}{\text {. }}$.

ii) for $C^{\prime \prime}<<0$, then $\frac{\partial q_{H}}{\partial \delta}>0$ as $\frac{\partial \Lambda_{H}}{\partial q_{S}}>0$ and $\frac{\partial \Lambda_{H}}{\partial q_{S}}>\overbrace{\frac{\partial \Lambda_{S}}{\partial q_{S}} \frac{\partial \Lambda_{H}}{\partial \delta}}^{<0} / \frac{\partial \Lambda_{S}}{\partial \delta}$.

Effect $\mu$ on $q_{H}$. From (12) we observe that the effect of $\mu$ on $q_{H}$ depends on the sign of $\frac{\partial \Lambda_{H}}{\partial \mu}=$ $C^{\prime}\left[\frac{q_{S}+q_{H}}{2}\right]-(1+\delta) \frac{C^{\prime}\left[q_{S}+q_{H}\right]}{2}, \frac{\partial \Lambda_{S}}{\partial \mu}=C^{\prime}\left[\frac{q_{S}+q_{H}}{2}\right]-C^{\prime}\left[q_{S}+q_{H}\right]$, and $\frac{\partial \Lambda_{H}}{\partial q_{S}}=-\frac{1-\mu}{2} C^{\prime \prime}\left[\frac{q_{S}+q_{H}}{2}\right]-$ $\frac{(1+\delta) \mu}{2} C^{\prime \prime}\left[q_{S}+q_{H}\right]$ (expression (A2)), as $\frac{\partial \Lambda_{S}}{\partial q_{S}}<0$ is assumed in (7). Thus,

i) for

$\checkmark C^{\prime \prime}>0$, then $\frac{\partial q_{H}}{\partial \mu}>0$ as $\frac{\partial \Lambda_{H}}{\partial \mu}>0$ (because $\delta=0$ is implied by $\frac{\partial q_{H}}{\partial \delta}<0$ ), $\frac{\partial \Lambda_{S}}{\partial \mu}<0$, and $\frac{\partial \Lambda_{H}}{\partial q_{S}}<0$ since $C^{\prime}\left[\frac{q_{S}+q_{H}}{2}\right]>\frac{C^{\prime}\left[q_{S}+q_{H}\right]}{2}$ is assumed,

$\diamond C^{\prime \prime}=0$, then $\frac{\partial q_{H}}{\partial \mu}>0$ as $\frac{\partial \Lambda_{H}}{\partial \mu}>0, \frac{\partial \Lambda_{S}}{\partial \mu}=0$, and $\frac{\partial \Lambda_{H}}{\partial q_{S}}=0$,

$\diamond C^{\prime \prime}<0$, then $\frac{\partial q_{H}}{\partial \mu}>0$ as $\frac{\partial \Lambda_{H}}{\partial \mu}>0, \frac{\partial \Lambda_{S}}{\partial \mu}>0$, and $\frac{\partial \Lambda_{H}}{\partial q_{S}}>0$,

ii) for $C^{\prime \prime}<<0$, then $\frac{\partial q_{H}}{\partial \mu}>0$ as $\frac{\partial \Lambda_{H}}{\partial \mu}>0, \frac{\partial \Lambda_{S}}{\partial \mu}>0$, and $\frac{\partial \Lambda_{H}}{\partial q_{S}}>0$.

In conclusion,

i) $(\mu, \delta)=(\delta, \delta)$ with $\delta \in[0,1)$ for $C^{\prime \prime}>0, C^{\prime \prime}=0$, or $C^{\prime \prime}<0$, because $\frac{\partial q_{H}}{\partial \delta}<0$ and $\frac{\partial q_{H}}{\partial \mu}>0$ implies that the constraint $\mu \leqslant \delta$ becomes binding.

ii) $(\mu, \delta)=(1,1)$ for $C^{\prime \prime}<<0$. 


\section{B Appendix: Feasible region with linear demand and linear marginal cost}

To compute the feasible region for our numerical simulation, we restrict attention to the relevant parameter range that comprises all the considered cases. Let us define the feasible region $R$ as a triple $\{\alpha, \theta, \lambda\}$ where $\alpha \in[4,6], \theta \in[-0.05,0.05]$, and $\lambda \in[1,1.8]$. Any parameter constellation in $R$ ensures positive quantities and marginal costs, along with compliance with second-order conditions.

\section{B.1 Positive of marginal cost}

In the cases of decreasing and constant returns (i.e., $C^{\prime \prime} \geqslant 0$ or, equivalently, $\theta \leqslant 0$ ), the marginal-cost function $C^{\prime}(q)=1-\theta q$ is always positive. In the presence of economies of traffic density (i.e., $C^{\prime \prime}<0$ or, equivalently, $\theta>0$ ), the most restrictive marginal cost function is $C^{\prime}\left(q_{S}+q_{H}\right)$, i.e., the one related to the hub-to-hub route. A sufficient condition ensuring $C^{\prime}\left(q_{S}+q_{H}\right)>0$ is to consider the maximum traffic volume on this route. Since from Proposition 2 we know that $\frac{\partial q_{S}}{\partial \mu}>0$ and $\frac{\partial q_{H}}{\partial \mu}>0$, the most restrictive case is $\mu=1$. Looking at the resulting marginal cost function for $\mu=1$, we obtain that $C^{\prime}\left(q_{S}+q_{H}\right)>0$ requires $\frac{9+2 \delta[3+2 \alpha \theta(4 \theta-1-2 \lambda)]+2 \alpha \theta(8 \theta-6-3 \lambda)+\delta^{2}(1-2 \alpha \theta \lambda)}{(3+\delta)^{2}-8 \theta(1+\delta)[(3+\delta)-\theta(1+\delta)]}>0$. In $R$, this condition is always observed since both the numerator and the denominator are positive.

\section{B.2 Positive quantities}

The equilibrium quantities with the considered demand and marginal cost functions are

$q_{S}=2(1+\delta) \frac{3(\alpha \lambda-3)+\theta[4-2 \alpha(\lambda-1-\mu)-\mu(1-\mu)]-\delta[3-\theta \mu(5-\mu)-\alpha \lambda(1-2 \theta \mu)]}{9+8 \theta^{2}-3 \theta(7+\mu)+\delta^{2}[1-5 \theta-\theta \mu(3-8 \theta)]+2 \delta\{3-\theta[11+5 \mu-4 \theta(1+\mu)]\}}$ and

$q_{H}=\frac{4(3+\delta)(\alpha-1)-4 \alpha \theta(1+\delta)[5-\lambda-\mu(\delta \lambda-1)]+8 \theta(1+\delta)+2 \mu(3+\delta)[1-\delta-\theta(1+\delta)]-2 \theta \mu^{2}\left(1-\delta^{2}\right)}{9+8 \theta^{2}-3 \theta(7+\mu)+\delta^{2}[1-5 \theta-\theta \mu(3-8 \theta)]+2 \delta\{3-\theta[11+5 \mu-4 \theta(1+\mu)]\}}$.

In $R$, it can be observed that $q_{S}>0$ and $q_{H}>0$ since both numerators and denominators are positive.

\section{B.3 Second-order conditions}

From the analysis of the second-order conditions, we obtain

$$
\begin{aligned}
& \frac{\partial^{2} \Pi^{i}}{\partial\left(p_{S}^{i}\right)^{2}}=\theta(5+\mu)(1+\delta)-4<0, \\
& \frac{\partial^{2} \Pi^{i}}{\partial\left(q_{H}^{i}\right)^{2}}=-\frac{(1-\delta) \theta \mu}{2}-1+\theta<0, \text { and }
\end{aligned}
$$




$$
\left(\frac{\partial^{2} \Pi^{i}}{\partial\left(p_{S}^{i}\right)^{2}}\right)\left(\frac{\partial^{2} \Pi^{i}}{\partial\left(q_{H}^{i}\right)^{2}}\right)-\left(\frac{\partial^{2} \Pi^{i}}{\partial p_{S}^{i} \partial q_{H}^{i}}\right)^{2}=[\theta(5+\mu)(1+\delta)-4]\left[-\frac{(1-\delta) \theta \mu}{2}-1+\theta\right]-[-\theta(1+\delta \mu)]^{2}>0 .
$$

In $R$, these conditions are always observed. 


\section{Figures and Tables}

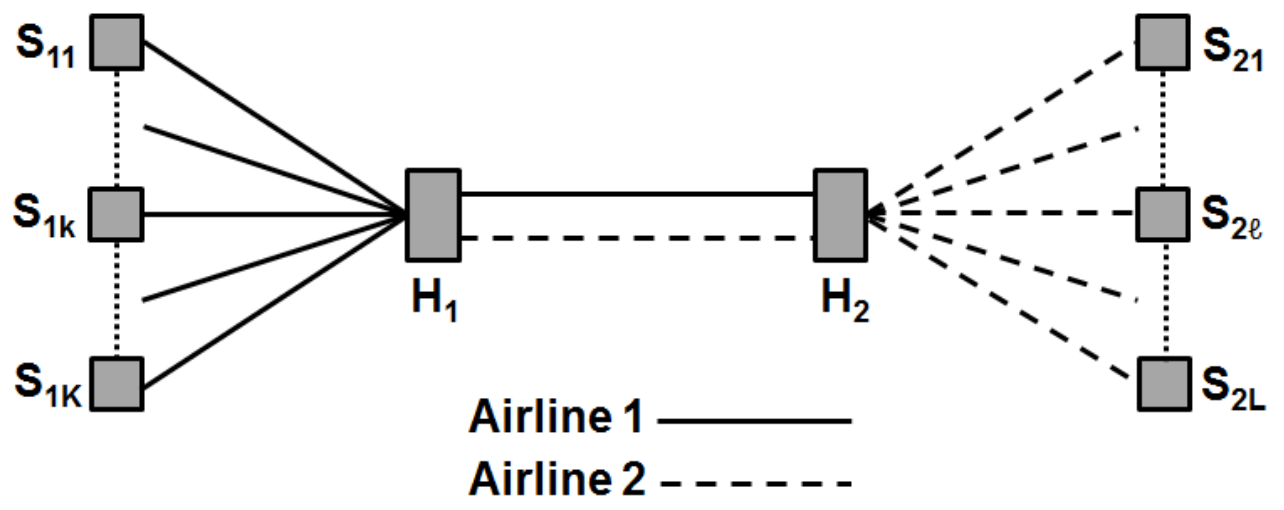

Fig. 1: The network

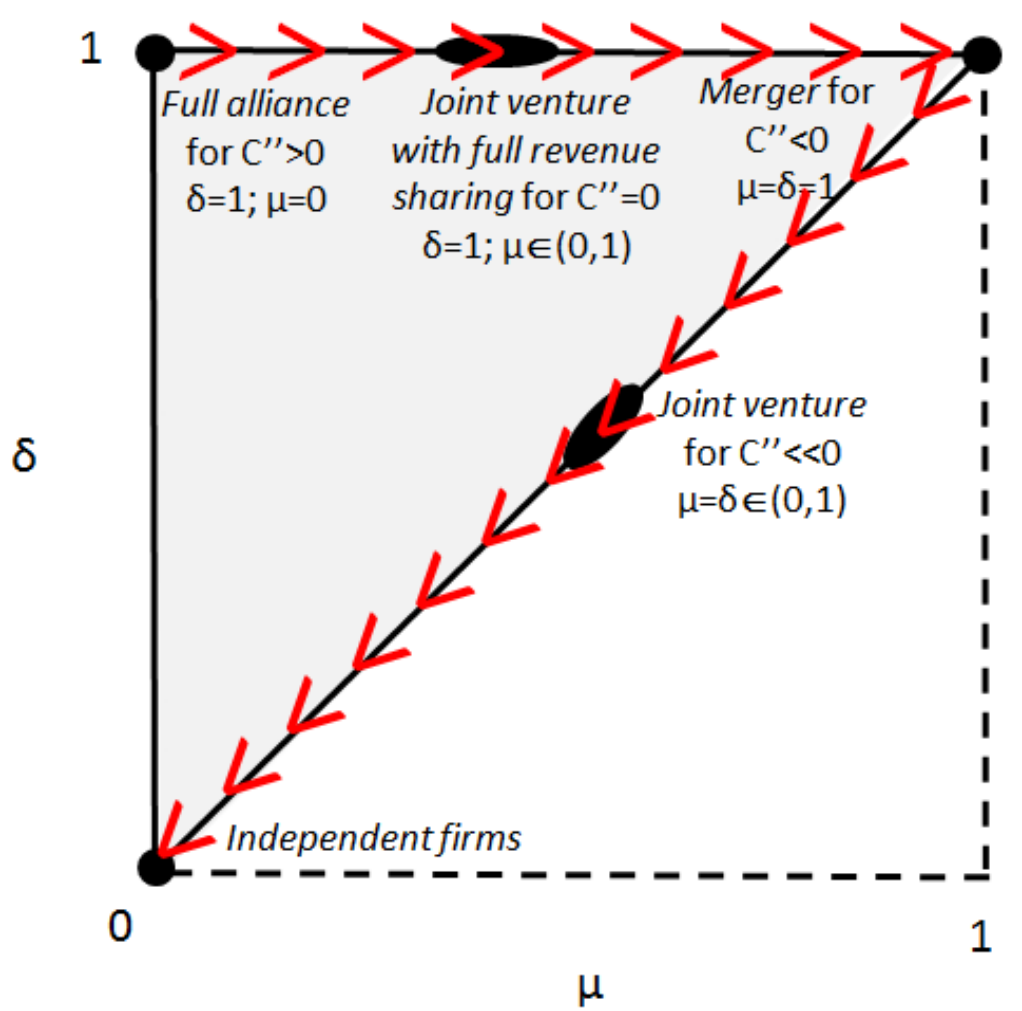

Fig. 2: Consumer-welfare maximizing cooperation agreements in market $\mathrm{S}$ (the arrows indicate the transition between cooperation agreements as $C^{\prime \prime}$ decreases) 


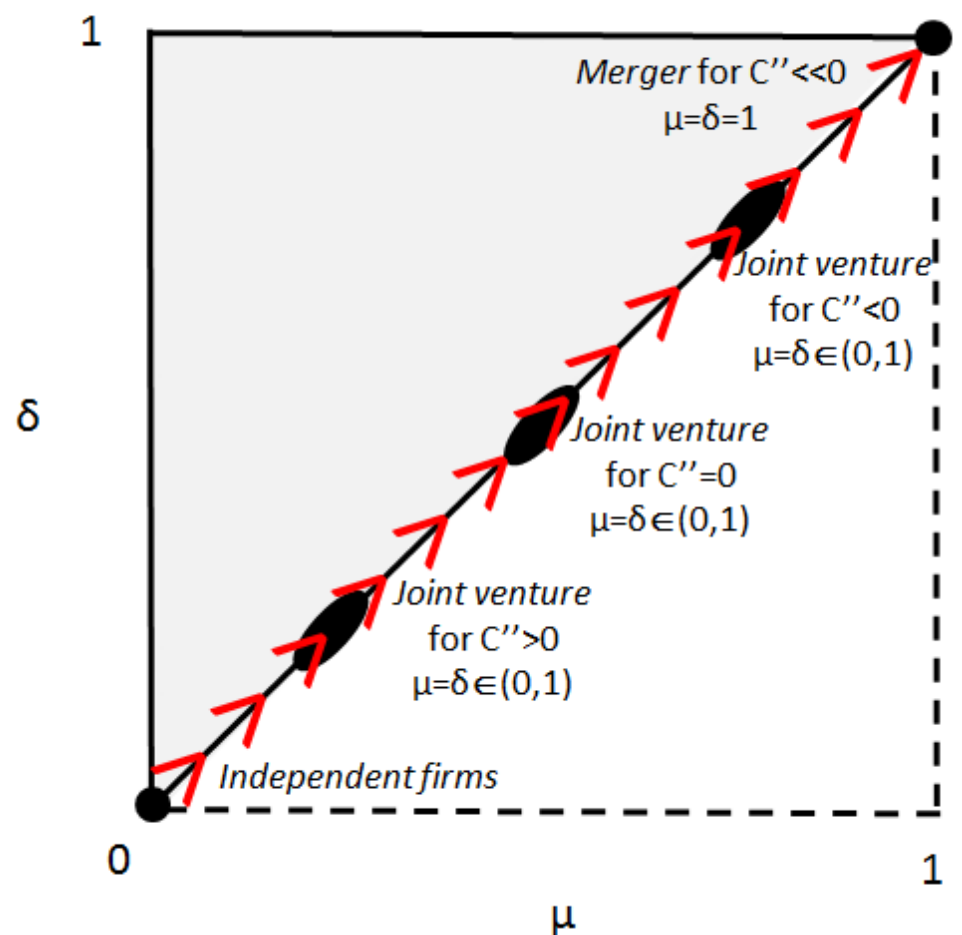

Fig. 3: Consumer-welfare maximizing cooperation agreements in market $\mathrm{H}$ (the arrows indicate the transition between cooperation agreements as $C^{\prime \prime}$ decreases) 


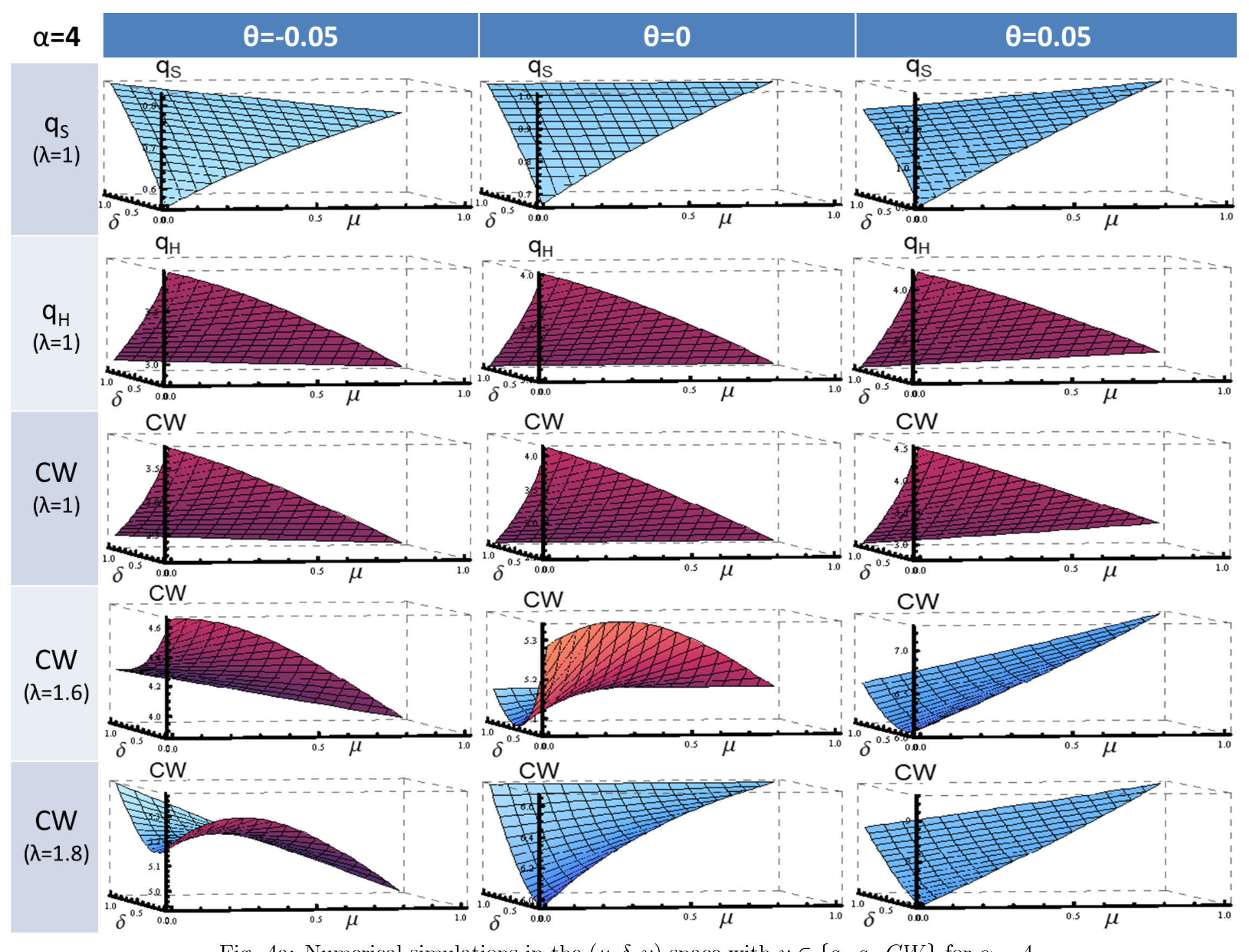

Fig. 4a: Numerical simulations in the $(\mu, \delta, v)$-space with $v \in\left\{q_{s}, q_{H}, C W\right\}$ for $\alpha=4$ 


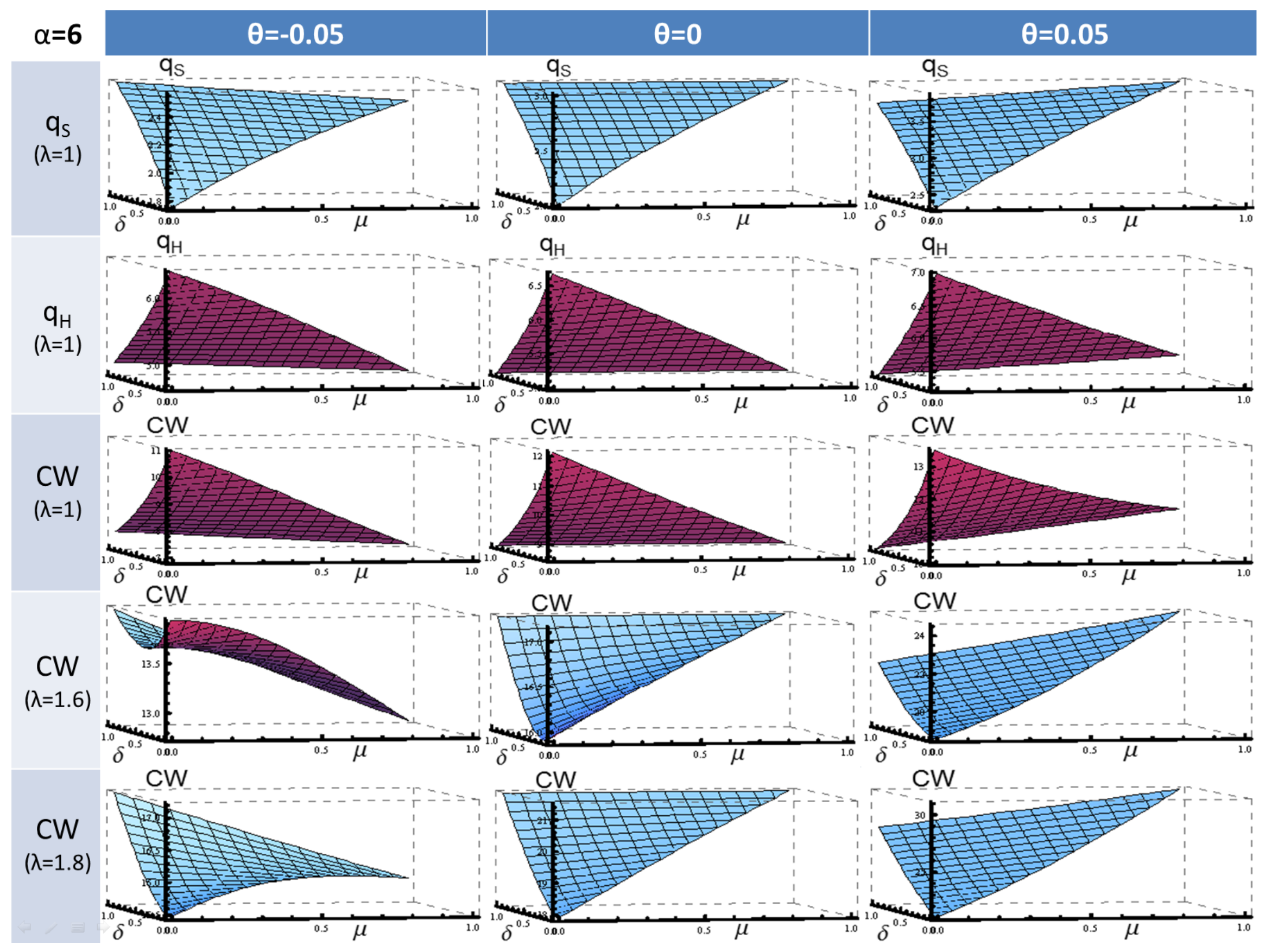

Fig. 4b: Numerical simulations in the $(\mu, \delta, v)$-space with $v \in\left\{q_{s}, q_{H}, C W\right\}$ for $\alpha=6$ 
Table 1. Some examples of airline cooperation agreements

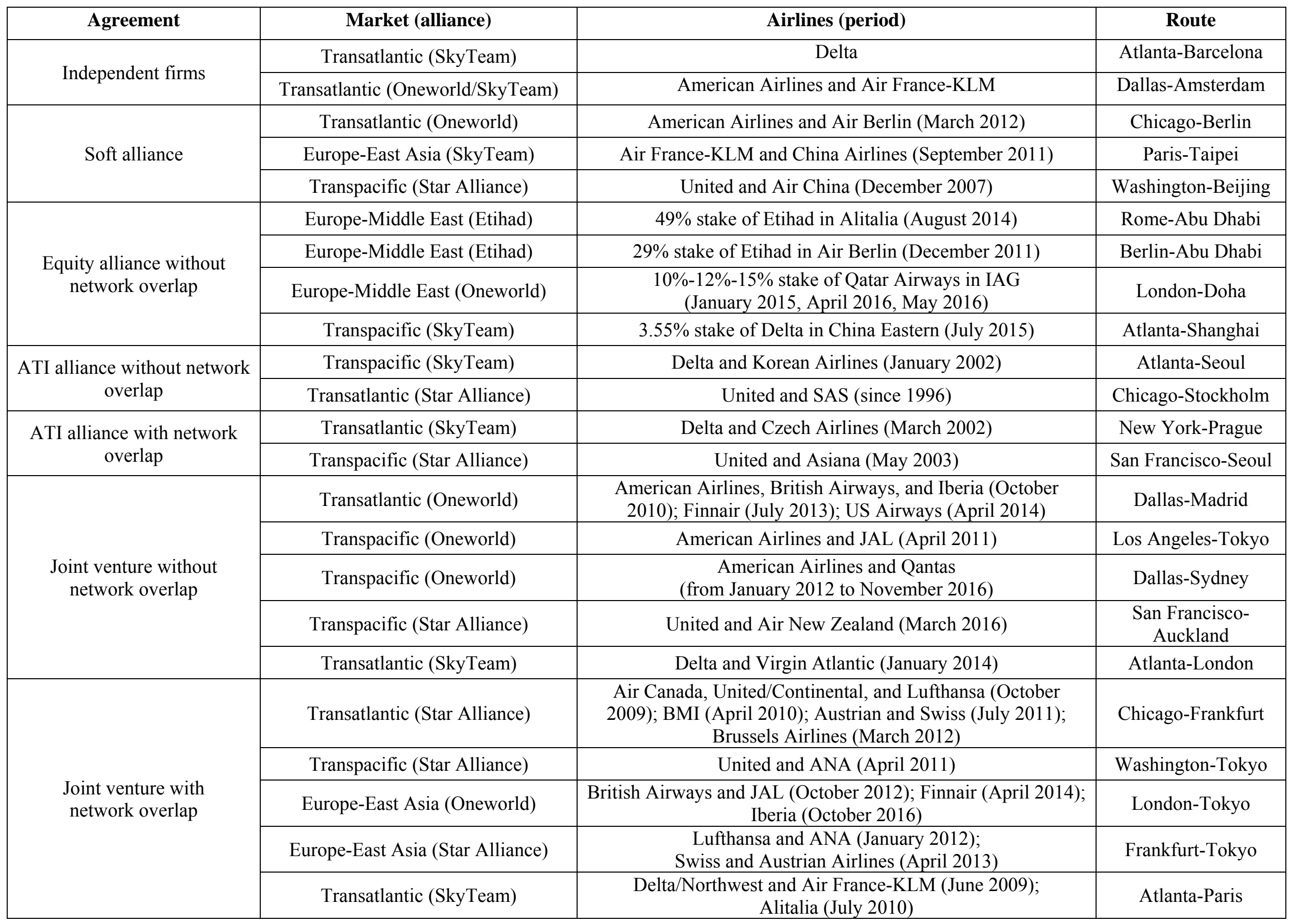


Table 2. Estimation results for interhub markets

\begin{tabular}{|c|c|c|c|c|c|c|c|c|c|c|}
\hline & \multicolumn{2}{|c|}{ Full sample } & \multicolumn{2}{|c|}{ Transatlantic market } & \multicolumn{2}{|c|}{ Thinnest routes } & \multicolumn{2}{|c|}{ Densest routes } & \multicolumn{2}{|c|}{$\begin{array}{c}\text { Congested airports } \\
\text { (US sample) }\end{array}$} \\
\hline & $\begin{array}{c}\text { First } \\
\text { approach }\end{array}$ & $\begin{array}{c}\text { Second } \\
\text { approach }\end{array}$ & $\begin{array}{c}\text { First } \\
\text { approach }\end{array}$ & $\begin{array}{l}\text { Second } \\
\text { approach }\end{array}$ & $\begin{array}{c}\text { First } \\
\text { approach }\end{array}$ & $\begin{array}{c}\text { Second } \\
\text { approach }\end{array}$ & $\begin{array}{c}\text { First } \\
\text { approach }\end{array}$ & $\begin{array}{c}\text { Second } \\
\text { approach }\end{array}$ & $\begin{array}{c}\text { First } \\
\text { approach }\end{array}$ & $\begin{array}{c}\text { Second } \\
\text { approach }\end{array}$ \\
\hline & (I) & (II) & (III) & (IV) & $(\mathrm{V})$ & (VI) & (VII) & (VIII) & (IX) & $(\mathrm{X})$ \\
\hline $\boldsymbol{\mu}$ & $-0.09(0.14)$ & $0.30(0.08)^{* * *}$ & $-0.32(0.24)$ & $0.45(0.09)^{* * *}$ & $-0.12(0.16)$ & $0.23(0.13)^{*}$ & $-0.06(0.42)$ & $0.37(0.17)^{* *}$ & $0.15(0.13)$ & $0.58(0.10)^{* * *}$ \\
\hline$\mu^{*} \psi$ & $0.13(0.12)$ & $0.01(0.07)$ & $0.34(0.20)^{* * *}$ & $-0.09(0.10)$ & $-0.01(0.19)$ & $-0.05(0.15)$ & $0.48(0.39)$ & $0.02(0.17)$ & $0.09(0.12)$ & $-0.09(0.09)$ \\
\hline$\delta$ & $0.43(0.13)^{* * *}$ & - & $0.84(0.25)^{* * *}$ & - & $0.37(0.14)^{* * *}$ & - & $0.49(0.43)$ & - & $0.49(0.12)^{* * *}$ & - \\
\hline$\delta * \psi$ & $-0.08(0.07)$ & - & $-0.310 .12)^{* * *}$ & - & $-0.006(0.09)$ & - & $-0.34(0.22)$ & - & $-0.13(0.07)^{* *}$ & - \\
\hline Pop & $0.20(0.13)$ & $0.19(0.13)$ & $-0.20(0.30)$ & $-0.22(0.31)$ & $0.52(0.23)^{* * *}$ & $0.52(0.23) * * *$ & $0.11(0.31)$ & $0.11(0.31)$ & $0.01(0.23)$ & $-0.01(0.23)$ \\
\hline GNI_pc & $0.18(0.20)$ & $0.17(0.20)$ & $0.62(0.86)$ & $0.45(0.92)$ & $0.90(0.29)^{* * *}$ & $0.91(0.30)^{* * *}$ & $0.27(0.36)$ & $0.29(0.36)$ & $-0.07(0.35)$ & $-0.07(0.35)$ \\
\hline Openess & $0.15(0.21)$ & $0.11(0.21)$ & $-0.002(0.43)$ & $0.02(0.44)$ & $-0.30(0.33)$ & $0.30(0.33)$ & $0.45(0.40)$ & $0.46(0.40)$ & $0.03(0.35)$ & $-0.008(0.35)$ \\
\hline Dist & $-1.81(0.29)^{* * * *}$ & $-1.79(0.29)^{* * *}$ & $-2.36(3.26)$ & $-3.04(3.29)$ & $-1.28(0.44)^{* * * *}$ & $-1.28(0.45)^{* * *}$ & $-2.41(0.57)^{* * *}$ & $-2.47(0.58)^{* * *}$ & $-1.11(0.35)^{* * *}$ & $-1.11(0.35)^{* * * *}$ \\
\hline$D^{\text {open_skies }}$ & $-0.03(0.15)$ & $-0.03(0.15)$ & - & - & $0.26(0.16)$ & $0.26(0.17)$ & $0.05(0.20)$ & $0.07(0.20)$ & $-0.37(0.17)^{* *}$ & $-0.37(0.17)^{* * *}$ \\
\hline Intercept & $19.99(3.88)^{* * *}$ & $20.21(3.86)^{* * *}$ & $23.55(31.95)$ & $31.48(32.88)$ & $6.31(6.53)$ & $6.31(6.53)$ & $23.07(8.69)^{* * *}$ & $23.41(8.76) * * *$ & $16.50(6.62)$ & $16.92(6.58)^{* * *}$ \\
\hline $\begin{array}{l}\text { Year } \\
\text { FE }\end{array}$ & YES & YES & YES & YES & YES & YES & YES & YES & YES & YES \\
\hline $\begin{array}{l}\text { Quarter } \\
\text { FE }\end{array}$ & YES & YES & YES & YES & YES & YES & YES & YES & YES & YES \\
\hline $\begin{array}{l}\text { Alliance } \\
\text { FE }\end{array}$ & YES & YES & YES & YES & YES & YES & YES & YES & YES & YES \\
\hline $\begin{array}{l}\text { City } \\
\text { FE }\end{array}$ & YES & YES & YES & YES & YES & YES & YES & YES & YES & YES \\
\hline $\mathrm{R}^{2}$ & 0.62 & 0.62 & 0.64 & 0.64 & 0.72 & 0.71 & 0.66 & 0.66 & 0.67 & 0.66 \\
\hline $\begin{array}{c}\text { F-test } \\
\text { (joint sig.) }\end{array}$ & $201.61 * * *$ & $165.54 * * *$ & $176.56^{* * *}$ & $151.45^{* * *}$ & $62.75^{* * *}$ & $63.30^{* * *}$ & $49.06^{* * *}$ & $49.55^{* * *}$ & $106.82^{* * *}$ & $107.54 * * *$ \\
\hline \# Obs. & 16897 & 16897 & 7556 & 7556 & 3046 & 3046 & 3163 & 3163 & 5231 & 5231 \\
\hline
\end{tabular}

Notes: Following the first approach, $\delta=0$ denotes independent firms and soft alliances, whereas $\delta=1$ applies to full alliances (i.e., ATI agreements and equity alliances) and joint ventures (including metal-neutral joint ventures). Following the second approach, $\delta=0$ also includes full alliances, whereas $\delta=1$ denotes joint ventures, which implies $\delta=\mu=1$ in the case of joint ventures and 0 otherwise.

Standard errors in parentheses (robust to heteroscedasticity and clustered by alliance-route). Statistical significance at $1 \%(* * *), 5 \%(* *), 10 \%(*)$. 
Table 3. Estimation results for interline markets

\begin{tabular}{|c|c|c|c|c|c|c|c|c|c|c|}
\hline & \multicolumn{2}{|c|}{ Full sample } & \multicolumn{2}{|c|}{ Transatlantic market } & \multicolumn{2}{|c|}{ Thinnest routes } & \multicolumn{2}{|c|}{ Densest routes } & \multicolumn{2}{|c|}{$\begin{array}{c}\text { Congested airports } \\
\text { (US sample) }\end{array}$} \\
\hline & $\begin{array}{c}\text { First } \\
\text { approach }\end{array}$ & $\begin{array}{c}\text { Second } \\
\text { approach }\end{array}$ & $\begin{array}{c}\text { First } \\
\text { approach }\end{array}$ & $\begin{array}{c}\text { Second } \\
\text { approach }\end{array}$ & $\begin{array}{c}\text { First } \\
\text { approach }\end{array}$ & $\begin{array}{c}\text { Second } \\
\text { approach }\end{array}$ & $\begin{array}{c}\text { First } \\
\text { approach }\end{array}$ & $\begin{array}{c}\text { Second } \\
\text { approach }\end{array}$ & $\begin{array}{c}\text { First } \\
\text { approach }\end{array}$ & $\begin{array}{c}\text { Second } \\
\text { approach }\end{array}$ \\
\hline & (I) & (II) & (III) & (IV) & $(\mathrm{V})$ & (VI) & (VII) & (VIII) & (IX) & (X) \\
\hline$\mu$ & $-0.13(0.21)$ & $0.67(0.12)^{* * *}$ & $-0.25(0.32)$ & $0.87(0.11)^{* * *}$ & $-0.21(0.46)$ & $0.72(0.20)^{* * *}$ & $-0.44(0.61)$ & $0.33(0.33)$ & $0.01(0.21)$ & $0.97(0.14)^{* * *}$ \\
\hline$\mu^{*} \psi$ & $0.43(0.15)^{* * *}$ & $-0.02(0.11)$ & $0.63(0.21)^{* * *}$ & $-0.05(0.13)$ & $0.35(0.51)$ & $-0.29(0.21)$ & $0.67(0.40)^{*}$ & $0.04(0.25)$ & $0.35(0.17)^{* * *}$ & $-0.12(0.12)$ \\
\hline$\delta$ & $0.90(0.20)^{* * *}$ & - & $1.23(0.33)^{* * *}$ & - & $0.99(0.42)^{* * * *}$ & - & $0.85(0.65)$ & - & $1.08(0.20)^{* * *}$ & - \\
\hline$\delta * \psi$ & $-0.33(0.10)^{* * *}$ & - & $-0.40(0.17)^{* * *}$ & - & $-0.32(0.23)$ & - & $-0.45(0.29)$ & - & $-0.36(0.10)^{* * *}$ & - \\
\hline$P o p$ & $0.12(0.21)$ & $0.09(0.21)$ & $0.62(0.40)$ & $0.58(0.40)$ & $0.59(0.31)^{*}$ & $0.49(0.30)$ & $0.26(0.43)$ & $0.24(0.43)$ & $-0.48(0.38)$ & $-0.53(0.38)$ \\
\hline$G N I \_p c$ & $0.20(0.26)$ & $0.18(0.26)$ & $3.31(0.99)^{* * *}$ & $3.00(1.08)^{* * * *}$ & $0.94(0.43)^{* *}$ & $0.86(0.43)^{* * *}$ & $0.54(0.46)$ & $0.54(0.45)$ & $0.13(0.52)$ & $0.11(0.55)$ \\
\hline Openess & $-0.32(0.31)$ & $-0.35(0.31)$ & $0.78(0.54)$ & $0.84(0.55)$ & $-0.30(0.55)$ & $-0.46(0.54)$ & $0.37(0.60)$ & $0.36(0.60)$ & $-0.45(0.53)$ & $-0.50(0.53)$ \\
\hline Dist & $-2.01(0.43)^{* * *}$ & $-2.00(0.44)^{* * *}$ & $-7.88(4.11)^{*}$ & $-8.72(4.21)^{* *}$ & $-0.59(0.76)$ & $-0.48(0.74)$ & $-3.49(1.00)^{* * *}$ & $-3.54(1.00)^{* * *}$ & $-1.31(0.54)^{* * *}$ & $-1.32(0.56)^{* * *}$ \\
\hline$D^{\text {open_skies }}$ & $0.13(0.22)$ & $0.11(0.22)$ & - & - & $0.59(0.30)^{*}$ & $0.62(0.35) *$ & $0.07(0.33)$ & $0.09(0.33)$ & $-0.22(0.31)$ & $-0.23(0.32)$ \\
\hline Intercept & $25.27(5.80)^{* * *}$ & $25.73(5.80)^{* * * *}$ & $35.05(39.01)$ & $45.83(40.75)$ & $0.61(10.10)$ & $1.79(9.70)$ & $30.34(11.89)^{* * * *}$ & $31.00(11.98)^{* * *}$ & $22.79(10.47)^{* * *}$ & $23.76(10.62)^{* * *}$ \\
\hline $\begin{array}{l}\text { Year } \\
\text { FE }\end{array}$ & YES & YES & YES & YES & YES & YES & YES & YES & YES & YES \\
\hline $\begin{array}{l}\text { Quarter } \\
\text { FE }\end{array}$ & YES & YES & YES & YES & YES & YES & YES & YES & YES & YES \\
\hline $\begin{array}{l}\text { Alliance } \\
\text { FE }\end{array}$ & YES & YES & YES & YES & YES & YES & YES & YES & YES & YES \\
\hline $\begin{array}{l}\text { City } \\
\text { FE }\end{array}$ & YES & YES & YES & YES & YES & YES & YES & YES & YES & YES \\
\hline $\mathrm{R}^{2}$ & 0.24 & 0.24 & 0.19 & 0.19 & 0.31 & 0.31 & 0.31 & 0.30 & 0.25 & 0.24 \\
\hline $\begin{array}{c}\text { F-test } \\
\text { (joint sig.) }\end{array}$ & $32.22 * * *$ & $31.97 * * *$ & $75.85^{* * *}$ & $19.93^{* * *}$ & $11.55^{* * *}$ & $11.54 * * *$ & $11.31^{* * *}$ & 11.44 & $17.40 * * *$ & $17.11^{* * *}$ \\
\hline \# Obs. & 16869 & 16869 & 7555 & 7555 & 3045 & 3045 & 3162 & 3162 & 5228 & 5228 \\
\hline
\end{tabular}

Notes: Following the first approach, $\delta=0$ denotes independent firms and soft alliances, whereas $\delta=1$ applies to full alliances (i.e., ATI agreements and equity alliances) and joint ventures (including metal-neutral joint ventures). Following the second approach, $\delta=0$ also includes full alliances, whereas $\delta=1$ denotes joint ventures, which implies $\delta=\mu=1$ in the case of joint ventures and 0 otherwise.

Standard errors in parentheses (robust to heteroscedasticity and clustered by alliance-route). Statistical significance at $1 \%(* * *), 5 \%(* *), 10 \%(*)$. 